\title{
Synthesis, Structures, and Photoinduced Electron Transfer Reaction in the 9,9'-Spirobifluorene-Bridged Bipolar Systems
}

\author{
Ken-Tsung Wong,* Sung-Yu Ku, Yi-Ming Cheng, Xiauo-Yun Lin, Ying-Yueh Hung, \\ Shih-Chieh Pu, Pi-Tai Chou,* Gene-Hsiang Lee, and Shie-Ming Peng \\ Department of Chemistry, National Taiwan University, Taipei 106, Taiwan \\ kenwong@ntu.edu.tw; chop@ntu.edu.tw
}

Received June 14, 2005

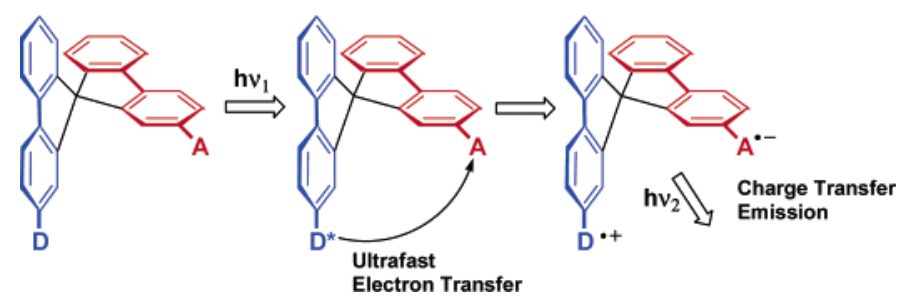

A series of 9,9'-spirobifluorene-bridged bipolar compounds $\mathbf{D} \boldsymbol{n} \mathbf{A} \boldsymbol{m}$ bearing various $n: m$ ratios for triarylamine (D) versus 1,3,4-oxadiazole-conjugated oligoaryl moiety (A) have been synthesized to investigate the corresponding photoinduced electron transfer (PET) property. The excitation behaviors were probed by steady-state absorption, emission, fluorescence solvatochromism, and femtosecond fluorescence up-conversion spectroscopy. The overall reaction dynamics can be rationalized by the rate of PET, in combination with solvent relaxation dynamics. It was found that the rate of PET is dependent on the anchored D/A ratio. The rate of D1A1 and D2A1 was resolved to be $\sim 2.44 \times 10^{12}$ and $2.32 \times$ $10^{12} \mathrm{~s}^{-1}$, respectively, while it is irresolvable in D1A2 and D2A2 $\left(>6.6 \times 10^{12} \mathrm{~s}^{-1}\right)$. In another approach, based on the comprehensive X-ray data, cyclic voltammetry, and absorption/emission spectra, the rate of photoinduced electron transfer was also qualitatively estimated. Fair comparisons were made between experimental and theoretical approaches to gain detailed insight into the PET for the titled systems.

\section{Introduction}

Bipolar (i.e., dual chromophores) organic materials have received considerable attention due to their potential uses in molecular devices such as molecular rectifiers, ${ }^{1}$ switches, ${ }^{2}$ electrochemical sensors ${ }^{3}$ photovoltaic cells, ${ }^{4}$ and nonlinear optical materials, ${ }^{5}$ etc. It has been a central interest to integrate such composite materials (or devices) via the modification of chromophores and linker structures so that the physical properties can be fine-tuned to a designated function. Recently, syntheses of materials aimed at increasing the dimensionality have been explored, among which the three-dimensional design based on spiro-bridged conjugated systems is of particular

(1) (a) Aviram, A.; Ratner, M. A. Molecular Rectifiers. Chem. Phys. Lett. 1974, 29, 277. (b) Molecular Electronics; Jortner, J., Ratner, M., Eds.; Blackwell Science: Oxford, UK, 1997. (c) Joachim, C.; Gimzewski, J. K.; Aviram, A. Nature 2000, 408, 541. (d) Metzger, R. M. Chem. Rev. 2000 103, 3803. (e) Majumder, C.; Mizuseki, H.; Kawazoe, Y. J. Phys. Chem. A 2001, 105, 9454.

(2) (a) Chen, J.; Reed, M. A.; Rawlett, A. M.; Tour, J. M. Science 1999, 286, 1550. (b) Molecular Switches; Feringa, B. L., Ed.: Wiley-VCH: New York, 2001. interest. $^{6}$ In a previous communication, ${ }^{7}$ we reported the synthesis and photophysical studies of a new type of 9,9'spirobifluorene-bridged bipolar system, in which the 1,3,4-

(3) (a) Pond, S. J. K.; Tsutsumi, O.; Rumi, M.; Kwon, O.; Zojer, E.; Brédas, J.-L.; Marder, S. R.; Perry, J. W. J. Am. Chem. Soc. 2004, 126, 9291. (b) Pearson, A. J.; Xiao, W. J. Org. Chem. 2003, 68, 536. (c) Kim, H. M.; Jeong, M.-Y.; Ahn, H. C.; Jeon, S.-J.; Cho, B. R. J. Org. Chem. 2004, 69, 5749. (d) Marcotte, N.; Plaza, P.; Lavabre, D.; Fery-Forgues, S.; Martin, M. M. J. Phys. Chem. A 2003, 107, 2394. (e) Miura, T.; Urano, Y.; Tanaka, K.; Nagano, T.; Ohkubo, K.; Fukuzumi, S. J. Am. Chem. Soc. 2003, 125, 8666. (f) Gabe, Y.; Urano, Y.; Kikuchi, K.; Kojima, H.; Nagano, T. J. Am. Chem. Soc. 2004, 126, 3357. (g) Sasaki, E.; Kojima, H.; Nishimatsu, H.; Urano, Y.; Kikuchi, K.; Hirata, Y.; Nagano, T. J. Am. Chem. Soc. 2005, 127, 3684 .

(4) (a) Cabanillas-Gonzalez, J.; Yeates, S.; Bradley, D. D. C. Synth. Met. 2003, 139, 637. (b) Pacios, R.; Bradley, D. D. C. Synth. Met. 2002, 127 261. (c) Velusamy, M.; Justin Thomas, K. R.; Lin, J. T.; Hsu, Y.-C.; Ho, K.-C. Org. Lett. 2005, 7, 1899.

(5) (a) Epshtein, O.; Eichen, Y.; Ehrenfreund, E.; Wohlgenannt, M.; Vardeny, Z. V. Phys. Rev. Lett. 2003, 90, 046804/1. (b) Zhan, X.; Liu, Y.; Zhu, D.; Liu, X.; Xu, G.; Ye, P. Chem. Phys. Lett. 2002, 362, 165. (c) Zhan, X.; Liu, Y.; Zhu, D.; Huang, W.; Gong, Q. Chem. Mater. 2001, 13 , 1540. (d) Lemaître, N.; Attias, A.-J.; Ledoux, I.; Zyss, J. Chem. Mater. 2001, 13, 1420. (e) Ishow, E.; Bellaïche, C.; Bouteiller, L.; Nakatani, K.; Delaire, J. A. J. Am. Chem. Soc. 2003, 125, 15744. 
SCHEME 1. The Synthesis of Bichromophore Compounds D1A2 and D2A2
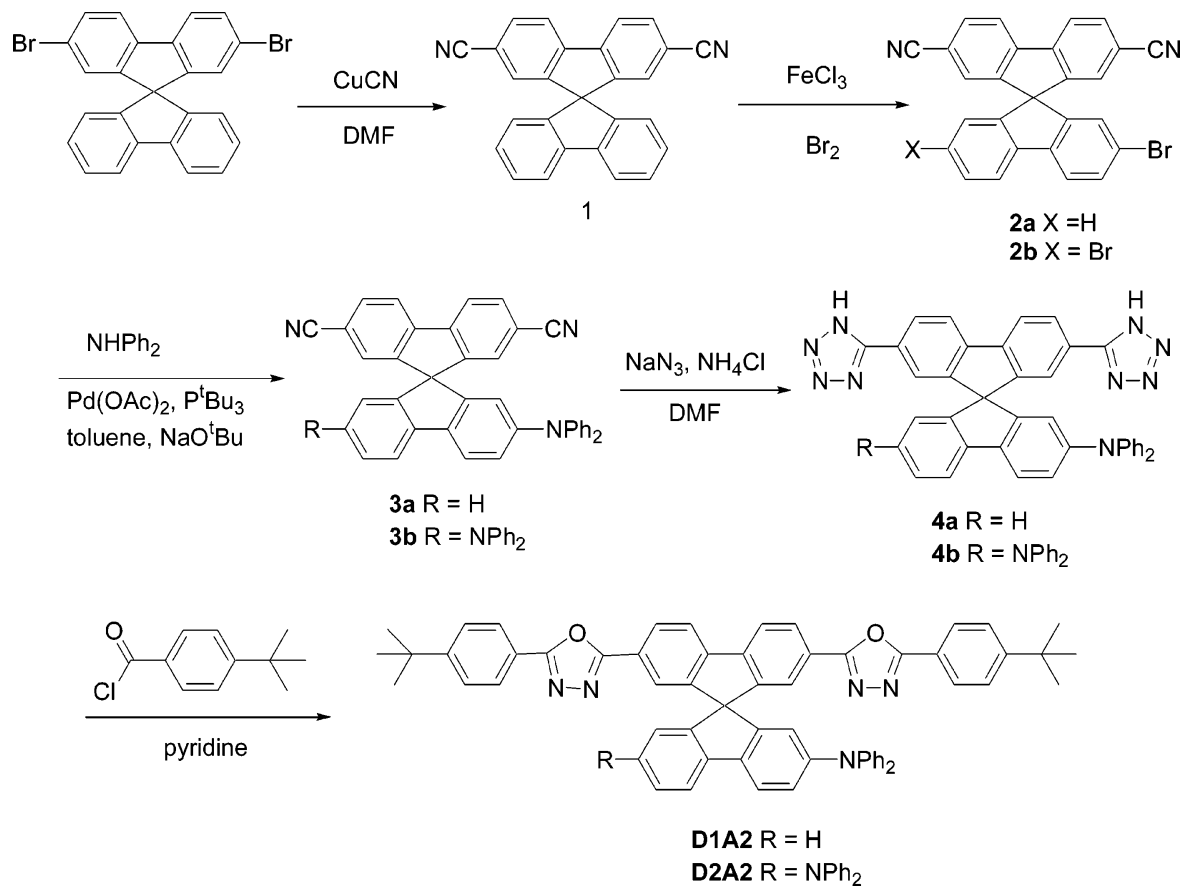

oxadiazole-containing conjugated oligoaryl moiety serves as the electron acceptor, while the triarylamine moiety acts as the donor counterpart. Such a configuration leads to the development of new materials with an interfacial layer of bifunctional properties. On the basis of steady-state approaches, salient photoinduced electron transfer (PET) takes place, resulting in a charge-transfer emission band. The results make further investigation necessary in order to gain more insights into the PET/solvation dynamics. In this article, a series of 9,9'-spirobifluorene-bridged bipolar compounds Dn A $\boldsymbol{m}$ bearing an $n: m$ ratio for triarylamine (D) versus 1,3,4-oxadiazole-conjugated oligoaryl moiety (A) have been synthesized to investigate the associated excitation behaviors such as the photoinduced electron transfer (PET) property, etc. The dynamics of PET was probed by the femtosecond fluorescence up-conversion spectroscopy in combination with structural, cyclic voltammetry, and absorption/emission approaches. Further comparisons made between experimental and theoretical approaches reveal a good consistency.

\section{Results and Discussion}

2.1. Synthesis. The synthetic pathways of $9,9^{\prime}$-spirobifluorene-bridged bipolar molecules D1A2 and $\mathbf{D 2 A 2}{ }^{7}$ are depicted in Scheme 1.

Treatment of 2,7-dibromo-9, $9^{\prime}$-spirobifluorene ${ }^{10}$ with $\mathrm{CuCN}$ in DMF at the reflux temperature gave the dicyano derivative 1 with an isolated yield of $90 \%$. The unsubstituted branch of $9,9^{\prime}$-spirobifluorene was then regioselectively brominated at C-2'

(6) (a) Saragi, T. P. I.; Pudzich, R.; Fuhrmann, T.; Salbeck, J. Appl. Phys. Lett. 2004, 84, 2334. (b) Spehr, T.; Pudzich, R.; Fuhrmann, T.; Salbeck, J. Org. Electrochem. 2003, 4, 61. (c) Sandin, Pi.; Martinez-Grau, A.; Sánchez, L.; Seoane, C.; Pou-AméRigo, R.; Orti, E.; Martin, N. Org. Lett. 2005, 7, 295.

(7) Chien, Y.-Y.; Wong, K.-T.; Chou, P.-T.; Cheng, Y.-M. Chem. Commun. 2002, 23, 2874.

(8) Chou, P.-T.; Chen, Y.-C.; Yu, W.-S.; Chou, Y.-H.; Wei, C.-Y.; Cheng, Y.-M. J. Phys. Chem. A 2001, 105, 1731.

(9) Chou, P.-T.; Yu, W.-S.; Cheng, Y.-M.; Pu, S.-C.; Yu, Y.-C.; Lin, Y.-C.; Huang, C.-H.; Chen, C.-T. J. Phys. Chem. A. 2004, 108, 6487. with 1 equiv of $\mathrm{Br}_{2}$ (in $\mathrm{CH}_{2} \mathrm{Cl}_{2}$ ) in the presence of Lewis acid, $\mathrm{FeCl}_{3}$, which was used as a promoter. The crude brominated products were directly subjected to a Pd-catalyzed amination ${ }^{11}$ with diphenylamine in the presence of a catalytic amount of $\mathrm{P}^{t} \mathrm{Bu}_{3}$ to give a $49 \%$ yield of $\mathbf{3 a}$ after column purification. Dibromination of dicyano derivative $\mathbf{1}$ was achieved by reacting it with an excess amount of $\mathrm{Br}_{2}$ in the presence of $\mathrm{FeCl}_{3}$ under refluxing in $\mathrm{CH}_{2} \mathrm{Cl}_{2}$ to afford $\mathbf{2 b}$ with an isolated yield of $87 \%$. $\mathrm{Pd}$-catalyzed amination of $\mathbf{2} \mathbf{b}$ gave triaryldiamine $\mathbf{3 b}$ in a yield of $75 \%$. The cyano groups in $\mathbf{3 b}$ were further converted to tetrazoles by treatment with $\mathrm{NaN}_{3}$ and $\mathrm{NH}_{4} \mathrm{Cl}$ in DMF at reflux temperature to form bistetrazole $\mathbf{4 b}$ in $80 \%$ yield. ${ }^{12}$ Subsequently, treating $\mathbf{4 b}$ with 4-tert-butylbenzoyl chloride in pyridine leads to the formation of the final spiro-configured bipolar compound D2A2 (73\%). Following a similar synthetic scheme to prepare D2A2, instead of isolating the tetrazole intermediate, the bipolar compound D1A2 was isolated in 34\% yield directly from 3a. In addition to the elemental analyses, which assigned the designated structural composition, the structures of D1A2 and D2A2 were further confirmed by single-crystal X-ray diffraction analysis elaborated in the following section.

For the synthesis of bipolar molecules D1A1 and D2A1, slighlty modified synthetic pathways (Scheme 2) were performed to selectively introduce the 1,3,4-oxadiazole counterpart. In this approach, the bromo group(s) used for Pd-catalyzed $\mathrm{C}-\mathrm{N}$ bond formation was directly from comercially available 2-bromofluorenone and 2,7-dibromofluorenone. Addition of an excess amount of Grignard reagent prepared from 2-iodo-4'-methyl-

(10) (a) Yu, W.-L.; Pei, J.; Huang, W.; Heeger, A. J. Adv. Mater. 2000 12, 828. (b) Wong, K.-T.; Chien, Y.-Y.; Chen, R.-T.; Wang, C.-F.; Lin, Y.-T.; Chiang, H.-H.; Hsieh, P.-Y.; Wu, C.-C.; Chou, C. H.; Su, Y. O.; Lee, G.-H.; Peng, S.-M. J. Am. Chem. Soc. 2002, 124, 11576.

(11) (a) Hartwig, J. F. Acc. Chem. Res. 1998, 31, 852. (b) Hartwig, J. F. Synlett 1997, 329. (c) Yang, B. H.; Buchwald, S. L. J. Organomet. Chem. 1999, 576, 125. (d) Buchwald, S. L. Acc. Chem. Res. 1998, 31, 805.

(12) (a) Alterman, M.; Anders, H. J. Org. Chem. 2000, 65, 7984. (b) Musser, J. H.; Kreft, A. F.; Bender, R. H. W.; Kubrak, D. M.; Grimes, D. J. Med. Chem. 1990, 33, 240. (c) Koguro, K.; Oga, T.; Mitsui, S.; Orita, R. Synthesis 1998, 6, 910. 
SCHEME 2. The Synthesis of Bichromophore Compounds D1A1 and D2A1

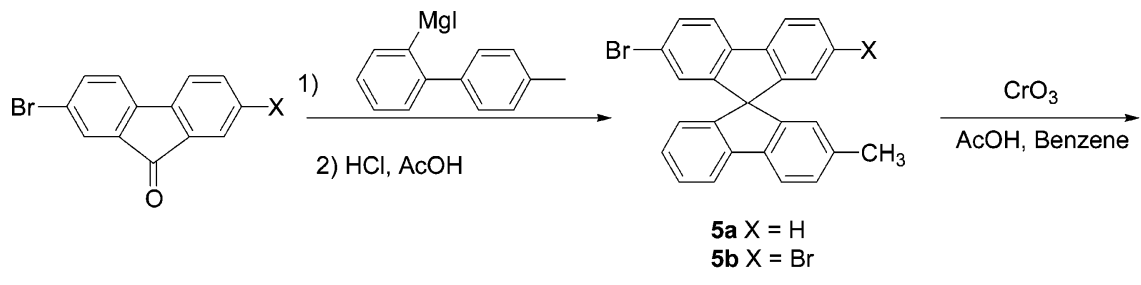

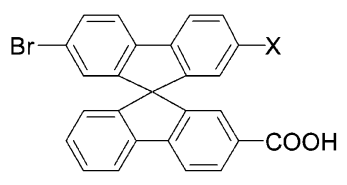

$6 \mathrm{a} X=\mathrm{H}$

$6 \mathbf{b} X=\mathrm{Br}$

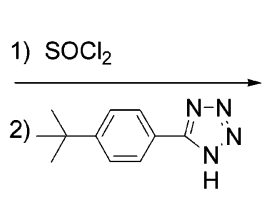

$\mathrm{H}$

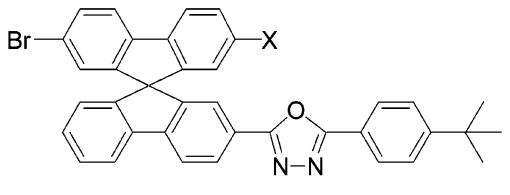

$7 \mathrm{a} X=\mathrm{H}$
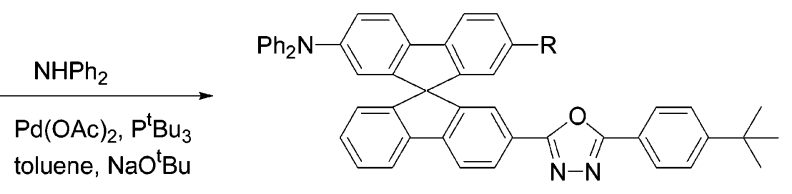

D1A1 $\mathrm{R}=\mathrm{H}$

D2A1 $\mathrm{R}=\mathrm{NPh}_{2}$

SCHEME 3. Structures of Monochromophore Model Compounds
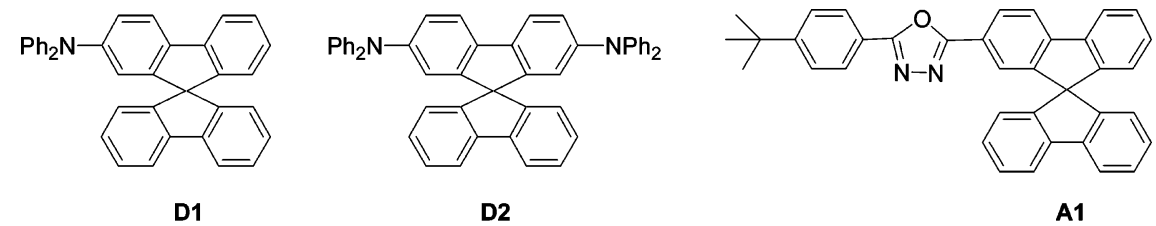

A1

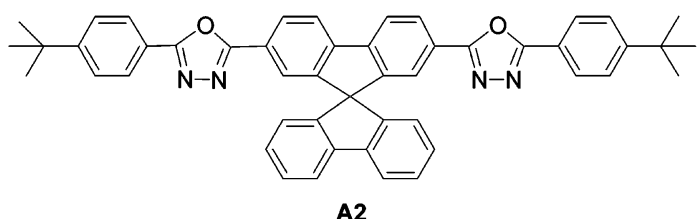

biphenyl ${ }^{13}$ into the THF solution of mono- and dibromofluorenone, followed by acid-promoted intramolecular FriedelCrafts cyclization, gave 2-bromo-2'-methyl-9,9'-spirobifluorene (5a) and 2,7-dibromo-2'-methyl-9,9'-spirobifluorene (5b) with $70 \%$ and $74 \%$ yield, respectively. Transformation of the methyl group in $\mathbf{5}$ into carboxylic acid was accomplished by oxidation with $\mathrm{CrO}_{3}$ in a mixed solvent of $\mathrm{AcOH}$ and benzene. ${ }^{14}$ Treatment of the resulting carboxylic group(s) with neat thionyl chloride gave acyl chloride, which was further reacted without purification with the corresponding tetrazole derivative in pyridine to give 1,3,4-oxadiazole-containing molecules 7a (65\%) and $\mathbf{7 b}(80 \%)$. The donor counterpart(s)-diphenylamino group(s) was (were) finally introduced by Pd-catalyzed amination described as above to give bipolar compounds D1A1 (71\%) and D2A1 (82\%). The structures of D1A1 and D2A1 were also further confirmed by single-crystal X-ray diffraction analyses.

(13) Airola, K.; Bartram, S.; Rissanen, K. J. Chem. Soc., Perkin Trans. $1 \mathbf{1 9 9 5}, 7,895$.

(14) Rock, D. A.; Boitano, A. E.; Wahlstrom, J. L.; Rock, D. A.; Jones, J. P. Bioorg. Chem. 2002, 30, 107.
For comparison, model compounds, such as D1, D2, A1, and A2 (see Scheme 3), were also synthezied via a similar synthetic protocol described in Schemes 1 and 2 (see the Supporting Information for experimental details and spectroscopic characterization).

2.2. Structures and Physical Properties: Molecular Structures. To unambiguously verify the chemical structures of these bipolar compounds, single crystals of D1A2, D2A2, D1A1, and D2A1 were obtained by layering and their structures were preliminarily determined (Figure 1, also see the Supporting Information for the detailed X-ray data, Table S-1). As depicted in Figure 1, the constituted chromophores (D and A) are arranged nearly orthogonal at the spiro center. The molecular geometry of the 1,3,4-oxadiazole ring makes the acceptor branches become nonlinear. A close inspection of the molecular geometries of D1A1, D1A2, D2A1, and D2A2 reveals the following interesting features. (1) For bipolar molecules with one acceptor such as D1A1 and D2A1, the acceptor branch bends toward the donor branch, positioning the oxygen atom in the 1,3,4-oxadiazole ring much closer to the donor counter- 
TABLE 1. HOMO-LUMO Energy Levels and Physical Properties of 9,9'-Spirobifluorene Configured Bichromophores and Their Corresponding Monochromophore Model Compounds

\begin{tabular}{|c|c|c|c|c|c|c|c|c|}
\hline & $T_{\mathrm{g}}\left(\mathrm{DSC},{ }^{\circ} \mathrm{C}\right)$ & $T_{\mathrm{d}}\left(\mathrm{TGA},{ }^{\circ} \mathrm{C}\right)$ & HOMO $(\mathrm{eV})$ & LUMO $(\mathrm{eV})$ & $\Delta E^{a}(\mathrm{eV})$ & $\lambda_{\mathrm{abs}^{b}(\mathrm{eV})}$ & $d^{c}(\AA)$ & $\Delta G^{d}(\mathrm{eV})$ \\
\hline D1 & 89 & 280 & -5.24 & -2.14 & 3.10 & & & \\
\hline D2 & 112 & 329 & -4.99 & -1.86 & 3.13 & & & \\
\hline A1 & 128 & 391 & -5.72 & -2.24 & 3.48 & & & \\
\hline A2 & 165 & 412 & -5.78 & -2.51 & 3.27 & & & \\
\hline D1A1 & 139 & 355 & -5.27 & -2.23 & 3.04 & 3.45 & $8.500(8)$ & -0.20 \\
\hline D1A2 & 187 & 436 & -5.22 & -2.51 & 2.71 & 3.41 & $7.881(6)$ & -0.56 \\
\hline D2A1 & 149 & 406 & -4.89 & -2.20 & 2.69 & 3.26 & $8.167(8)$ & -0.40 \\
\hline D2A2 & 173 & 442 & -5.03 & -2.49 & 2.54 & 3.23 & $7.754(5)$ & -0.55 \\
\hline
\end{tabular}

${ }^{a}$ The optical band gap estimated by the absorption onset. ${ }^{b}$ The first vibronic peak of the absorption spectrum. ${ }^{c} d$ indicates the center-to-center distance of the donor and acceptor. ${ }^{d}$ The Gibbs free energies change $(\Delta G)$ accompanying photoinduced electron transfer for the donor-acceptor systems was calculated in cyclohexane.
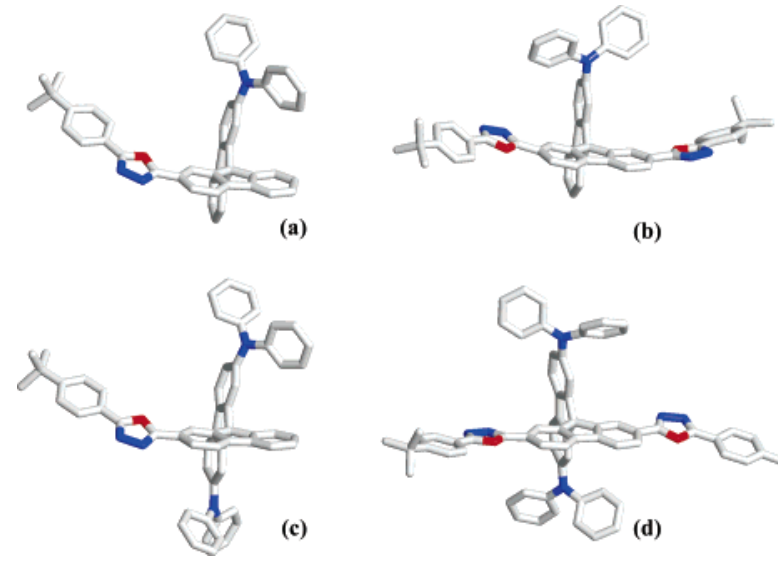

(b)

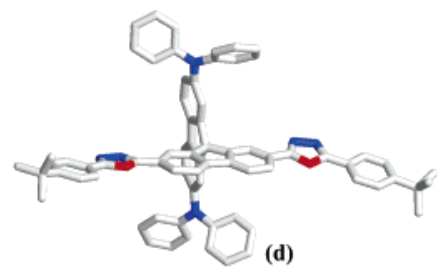

FIGURE 1. Molecular structures of 9,9'-spirobifluorene configured bipolar molecules (a) D1A1, (b) D1A2, (c) D2A1, and (d) D2A2. Hydrogen atoms and solvent molecules are omitted for presentation clarity.

part. (2) For D2A2, the acceptor bends away from the donor branch, making two oxadiazole rings adopt a cis configuration. (3) Bipolar compounds with two oxadiazole rings (D1A2 and D2A2) show different molecular geometries. The two oxygen atoms of oxadiazole rings in D1A2 position as a trans configuration, whereas D2A2 has a cis configuration. However, despite the different configuration of the composed acceptor chromophores in the DnAm system, the distances between the nitrogen atom of the triarylamine (donor) and the center of oxadiazole ring (acceptor) can be calculated (Table 1).

Morphological and Thermal Properties. Differential scanning calorimetry (DSC) was used for probing the morphological properties of the solid samples of these materials including their monochromophore model compounds. All bipolar compounds and their monochromophore model compounds exhibit distinct glass transition temperatures $\left(T_{\mathrm{g}}\right)$ ranging from 89 to $187{ }^{\circ} \mathrm{C}$ (Table 1). As shown in Table 1, bichromophore compounds normally exhibit higher $T_{\mathrm{g}}$ values than those of monochromophore model compounds, the results of which can be attributed to the higher molecular weight of bipolar molecules. ${ }^{15}$ TGA analysis also indicates that these compounds are thermally stable with decomposition temperatures $\left(T_{\mathrm{d}}\right)$, relative to a $5 \%$ weight loss, ranging from 280 to $442{ }^{\circ} \mathrm{C}$ (Table 1). The relatively high $T_{\mathrm{g}}$ together with high thermal tolerance makes them feasible to form good quality thin films by high vacuum deposition, which is crucial for further applications of these bipolar materials as active components in optoelectronic devices.

(15) Yin, S. W.; Shuai, Z.; Wang, Y. J. Chem. Inf. Comput. Sci. 2003 $43,970$.
Cyclic Voltammetry (CV). Cyclic voltammetry measurements for the DnAm system as well as the monochromophore model compounds have been performed (see the Supporting Information, Table S-2). The electrochemical behaviors of certain spirobifluorene-configured bipolar compounds investigated by $\mathrm{CV}$ and their applications in electrochemically generated luminescence (ECL) have been reported previously. ${ }^{16}$ On the basis of the data of $\mathrm{CV}$ and absorption spectra, the corresponding HOMO and LUMO energy levels were deduced and the results are summarized in Table 1 (details for the calculations of HOMO and LUMO energy levels using CV and absorption band gap are given in the Supporting Information). As indicated in Table 1, the energy levels of the associated frontier orbitals for bichromophore compounds are slightly shifted as compared to those of monochromophore model compounds. The difference could be reasonably attributed to a weak Coulombic interaction between the donor(s) and acceptor(s), which are now chemically linked/bonded through a spiro carbon. With such a configuration, the tetrahedral C-9 carbon of fluorene serves as an insulating spacer, which effectively restricts the extension of $\pi$-conjugation. Accordingly, as also supported by the absorption spectroscopy (vide infra), negligibly small charge transfer occurs between the constituted D/A chromophores at the ground state. However, the favorable photoinduced electron transfer can be anticipated by the relative alignment of energy levels of the D/A chromophores shown in Figure 2.

3.3. Steady-State Photophysical Approaches. The absorption and emission spectra of these bipolar DnAm systems were studied in different organic solvents (Table 2). Figure 3 depicts the steady-state absorption and emission spectra of the corresponding D1A1 as an example in various solvents (for D1A2, D2A1, and D2A2 see Figures S-5 to S-7 in the Supporting Information). For all studied $\mathbf{D} \mathbf{n} \mathbf{A} \boldsymbol{m}$ systems the absorption spectral features can be well convoluted by a linear combination of $\mathrm{D}$ and $\mathrm{A}$ chromophores (not shown here), indicating a negligibly small interaction between $\mathrm{D}$ and $\mathrm{A}$, so that $\mathrm{D}$ and $\mathrm{A}$ can be treated as separated entities in the ground state. Furthermore, in all DnAm systems the absorption peak wavelength exhibits nearly solvent polarity independence. The results lead us to conclude a similar solvation effect between the ground and Franck-Condon excited state. In other words, the FranckCondon excited state is subject to a rather small dipolar change with respect to the ground state.

In sharp contrast, the emission spectra of all DnAm composites show strong solvent-polarity dependence, revealing a dominant broad emission band that undergoes remarkable

(16) Fungo, F.; Wong, K.-T.; Ku, S.-Y.; Hung, Y.-Y.; Bard, A. J. J. Phys. Chem. B 2005, 109, 3984 . 


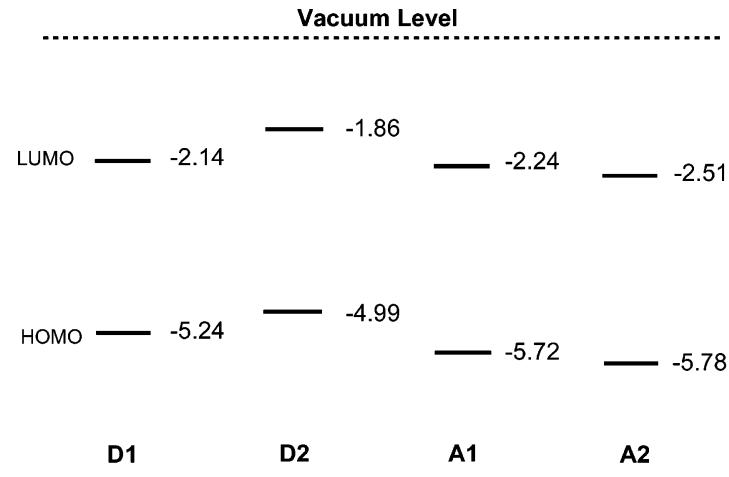

(a)

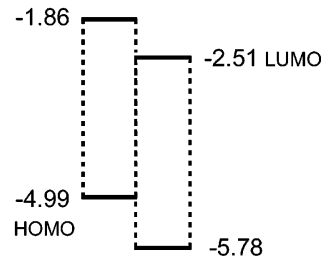

D2 A2

(b)

FIGURE 2. (a) HOMO-LUMO energy levels of monochromophore model compounds D1, D2, A1, and A2. (b) A representative example of energy level alignment of 9,9'-spirobifluorene bridged bichromophore (D2A2).

TABLE 2. The Photophysical Properties of the DnAm Systems in Various Solvents ${ }^{a}$

\begin{tabular}{cccc}
\hline & & degassed \\
& $\lambda_{\text {fluorescence }}(\mathrm{nm})$ & Q & \\
lifetime $(\mathrm{ns})$ & Q.Y. $(\Phi)$ \\
\hline D1A1 & & & \\
CYC & 394 & 9.11 & $2.79 \times 10^{-1}$ \\
BEN & 448 & 24.25 & $5.86 \times 10^{-2}$ \\
THF & 484 & 22.60 & $2.83 \times 10^{-2}$ \\
DCM & 510 & 9.87 & $1.96 \times 10^{-2}$ \\
ACN & 556 & 1.37 & $7.62 \times 10^{-3}$ \\
D1A2 & & & \\
CYC & 440 & 12.91 & $1.12 \times 10^{-1}$ \\
BEN & 490 & 105.11 & $1.04 \times 10^{-1}$ \\
THF & 545 & 95.12 & $9.66 \times 10^{-2}$ \\
DCM & 555 & 82.30 & $5.59 \times 10^{-2}$ \\
ACN & 600 & 73.17 & $2.40 \times 10^{-2}$ \\
D2A1 & & & \\
CYC & 440 & 13.91 & $1.60 \times 10^{-1}$ \\
BEN & 490 & 28.16 & $1.19 \times 10^{-1}$ \\
THF & 520 & 26.54 & $8.11 \times 10^{-2}$ \\
DCM & 560 & 22.90 & $4.54 \times 10^{-2}$ \\
ACN & 595 & 20.00 & $1.11 \times 10^{-2}$ \\
D2A2 & & & \\
CYC & 500 & 18.25 & $4.49 \times 10^{-2}$ \\
BEN & 557 & 42.09 & $3.57 \times 10^{-2}$ \\
THF & 588 & 37.77 & $1.08 \times 10^{-2}$ \\
DCM & 609 & 20.66 & $5.20 \times 10^{-3}$ \\
ACN & 642 & 6.45 & $1.08 \times 10^{-3}$ \\
CYC & & &
\end{tabular}

${ }^{a} \mathrm{CYC}$ : cyclohexane. BEN: benzene. THF: tetrahydrofurane. DCM: dichloromethane. CAN: acetonitrile.

bathochromic shifts with an increase of the solvent polarity. For example, D1A1 displays a $394 \mathrm{~nm}$ emission band in cyclohexane, which is then red shifted to as far as $556 \mathrm{~nm}$ in acetonitrile. In all solvents studied, the excitation spectra are effectively identical with the absorption profiles, excluding their origin from traces of impurity. Detailed analyses revealed that the intensity of the emission was linearly proportional to the studied concentrations in the range of $10^{-5}-10^{-4} \mathrm{~mol} \mathrm{dm} \mathrm{dm}^{-3}$. Thus, the possibility of the emission resulting from the aggregation effect can also be eliminated. It is also important to note that none of the emission resembles either $\mathbf{D n}$ or $\mathbf{A m}$ emission spectrum in cyclohexane, discarding its origin from the energy transfer process. Since cyclohexane is normally considered as a nonpolar solvent, in which the solvent dipolar relaxation is negligible, the large Stokes shifted emission in cyclohexane cannot be merely due to the solvent relaxation. Furthermore, the emission peak wavelength of 394 (D1A1), 440 (D1A2), 440 (D2A1), and $500 \mathrm{~nm}$ (D2A2) in cyclohexane

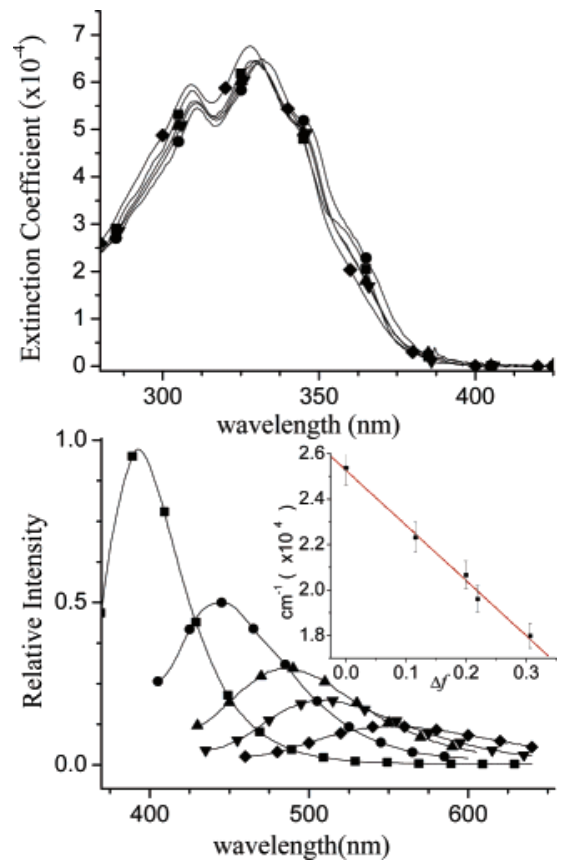

FIGURE 3. Static absorption and fluorescence spectra of D1A1 in

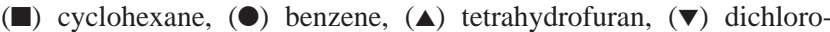
methane, and $(\diamond)$ acetonitrile at $298 \mathrm{~K}$. Inset: The plot of emission peak frequencies as a function of solvent polarities.

correlates very well with the energy difference (in $\mathrm{nm}$ ) between Am (LUMO) and Dn (HOMO) of 405 (D1A1), 457 (D1A2), 460 (D2A1), and $488 \mathrm{~nm}$ (D2A2) calculated from CV measurements (see the Supporting Information, Table S-2).

Gathering data from both absorption and emission spectroscopy, it is thus very unlikely to attribute the emission simply to a solvatochromism process, in which a gigantic change of dipole moment (or an instant charge transfer/redistribution) takes place upon Franck-Condon excitation, i.e., a kind of optical transfer process. ${ }^{9}$ Alternatively, the results can be more plausibly rationalized by a mechanism incorporating a fast photoinduced electron transfer (PET) process, resulting in a large change of dipole moment in the excited state. Subsequently, due to the unstable solvation environment, the solvent relaxation process takes place, resulting in the solvent-polarity dependent emission, i.e., the fluorescence solvatochromism.

This viewpoint can first of all be supported by the free-energy change $(\Delta G)$ for photoinduced electron transfer between an 
excited donor molecule (D*) and a ground-state acceptor (A) expressed as:

$$
\begin{array}{r}
\Delta G=E_{\mathrm{ox}}(\mathrm{D})-E_{\mathrm{red}}(\mathrm{A})-E_{00}(\mathrm{D})-\left(e^{2} / \epsilon d\right)- \\
\left(e^{2} / 2\right)\left(1 / r_{\mathrm{D}^{+}}+1 / r_{\mathrm{A}^{-}}\right)\left(1 / \epsilon_{\mathrm{r}}-1 / \epsilon\right)
\end{array}
$$

where $E_{\mathrm{ox}}(\mathrm{D})$ and $E_{\mathrm{red}}(\mathrm{A})$ are the oxidation and reduction potentials of triarylamine and 1,3,4-oxadiazole moieties, respectively, $E_{00}(\mathrm{D})$ is the energy of zero-zero transition of the donor, $r_{\mathrm{D}^{+}}$and $r_{\mathrm{A}^{-}}$are effective ionic radii for $\mathrm{D}^{+}$and $\mathrm{A}^{-}$, respectively, $\epsilon$ is the dielectric constant of solvent, and $d$ is the center-to-center distance between D and A. $E_{\text {ox }}$ and $E_{\text {red }}$ for $\mathrm{D} \boldsymbol{n} \mathbf{A} \boldsymbol{m}$ were measured by cyclic voltammetry. $E_{00}$ was obtained from the first vibronic peak of the absorption spectrum. Furthermore, according to the X-ray structure, the center-tocenter distance between D (nitrogen atom) and A (center of 1,3,4-oxadiazole) for all $\mathbf{D} \boldsymbol{n} \mathbf{A} \boldsymbol{m}$ systems can be accurately estimated (Table 1). A semiempirical PM3 approximation was further performed, giving $r_{\mathrm{D}^{+}} \sim r_{\mathrm{A}^{-}}=5.3 \AA$. With all values substituted into eq 1 , the free energies of ET $(\Delta G)$ in cyclohexane were then calculated and the results are listed in Table 1 . As indicated by the negative $\Delta G$ values, the excited state ET reaction is apparently an exergonic process in all $\mathbf{D} \boldsymbol{n} \mathbf{A} \boldsymbol{m}$ systems applied. Further details regarding dynamics of PET are elaborated in the following section of femtosecond approaches.

Owing to the electron transfer process, the excited-state dipole moment can thus be drastically different from that of the ground state. If the dipole moments of the solute are approximated by a point dipole in the center of a spherical cavity with a radius $a_{0}$, on the basis of small solvent-dependent absorption properties and negligence of the solute polarizability, one obtains

$$
\tilde{v}_{\mathrm{f}}=\tilde{v}_{\mathrm{f}}^{\mathrm{vac}}-\frac{2\left(\vec{\mu}_{\mathrm{e}}-\vec{\mu}_{\mathrm{g}}\right)^{2}}{h c a_{0}{ }^{3}} \Delta f
$$

where $\tilde{v}_{\mathrm{f}}$ and $\tilde{\mathrm{v}}_{\mathrm{f}}^{\text {vac }}$ in eq 2 are the spectral position (in terms of wavenumber) of the solvation equilibrated fluorescence maxima and the value extrapolated to the diluted gas phase, respectively, $\vec{\mu}_{\mathrm{g}}$ and $\vec{\mu}_{\mathrm{e}}$ are the dipole moment vectors of the ground and excited states, and $\Delta f$ is the solvent polarity parameter function and is generally expressed as $\Delta f=(\epsilon-1) /(2 \epsilon+1)$, where $\epsilon$ denotes the static dielectric constant of the solvent. The plot of the fluorescence peak frequency as a function of $\Delta f$ for $\mathbf{D} \boldsymbol{n} \mathbf{A} \boldsymbol{m}$ is shown in Figures $3-5$. As predicted by eq 2, a linear relationship is found from cyclohexane to acetonitrile, and slopes as steep as $-24096,-18090,-18512$, and $-14200 \mathrm{~cm}^{-1}$ were obtained for complexes D1A1, D1A2, D2A1, and D2A2, respectively, consistent with its assignment of the charge-transfer emission. $a_{0}$ in eq 2 was estimated to be 7.69 (D1A1), 8.36 (D1A2), 8.27 (D2A1) and), $8.84 \AA$ A (D2A2) via the semiempirical method PM3. Accordingly, the change in dipole moment between ground and excited states was deduced to be as large as 32.8 (D1A1), 32.2 (D1A2), 32.1 (D2A1), and 31.0 D (D2A2).

3.4. Femtosecond Dynamics. Due to the lack of emission originating from either $\mathbf{D} \boldsymbol{n}$ or $\mathbf{A} \boldsymbol{m}$ in the steady-state approach, the dynamics of photoinduced electron transfer in the $\mathbf{D} \boldsymbol{n} \mathbf{A m}$ system is expected to be fast. This viewpoint can be further supported by the corresponding PET dynamics in various solvents. Accordingly, an attempt has been made to gain more insights into the relaxation dynamics of the $\mathbf{D} \mathbf{n} \mathbf{A} \boldsymbol{m}$ systems via the fluorescence up-conversion technique. Figure 4 depicts the time-resolved traces of D2A1 in benzene. Detailed fitting

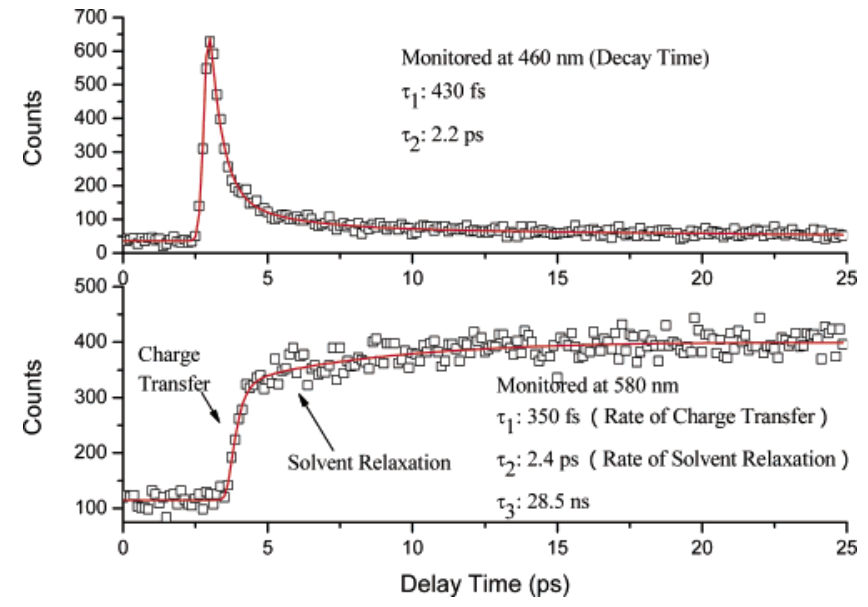

FIGURE 4. Time-resolved sum frequency signal of fluorescence (upper 460 and lower $580 \mathrm{~nm}$ ) and gate pulse $(760 \mathrm{~nm}$ ) for D2A1 in benzene. The solid lines express the corresponding best-fitted curves.

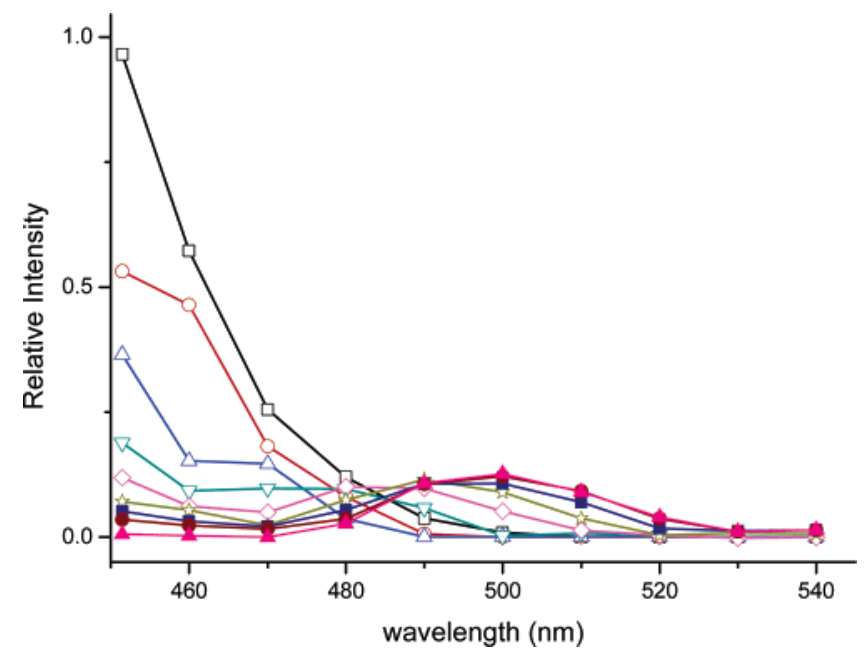

FIGURE 5. The temporal spectral evolution of D2A1 in benzene acquired at a delay time of $(\square) 250 \mathrm{fs},(\bigcirc) 500 \mathrm{fs},(\triangle) 1 \mathrm{ps},(\nabla) 1.5 \mathrm{ps}$,

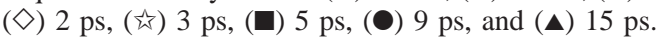

TABLE 3. The Photophysical Properties of DnAm Systems in Benzene $^{a}$

\begin{tabular}{cc}
\hline compd & \multicolumn{1}{c}{ dynamics } \\
\hline D1A1 & $460 \mathrm{~nm}\left[\tau_{:}: 0.41 \mathrm{ps}(0.623), \tau_{2}: 1.93 \mathrm{ps}(0.377)\right]$ \\
& $520 \mathrm{~nm}\left[\tau_{1}: 0.38 \mathrm{ps}(-0.162), \tau_{2}: 2.3 \mathrm{ps}(-0.172)\right.$, \\
& $\left.\tau_{3}: 24.25 \mathrm{~ns}(0.666)\right]$ \\
D1A2 & $460 \mathrm{~nm}\left[\tau_{0}: 0.14 \mathrm{ps}(0.916), \tau_{2}: 4.43 \mathrm{ps}(0.084)\right]$ \\
& $520 \mathrm{~nm}\left[\tau_{1}: 0.18 \mathrm{ps}(-0.155), \tau_{2}: 3.3 \mathrm{ps}(-0.101)\right.$, \\
& $\left.\tau_{3}: 105.11 \mathrm{~ns}(0.744)\right]$ \\
D2A1 & $460 \mathrm{~nm}\left[\tau_{1}: 0.43 \mathrm{ps}(0.853), \tau_{2}: 2.2 \mathrm{ps}(0.147)\right]$ \\
& $580 \mathrm{~nm}\left[\tau_{1}: 0.35 \mathrm{ps}(-0.315), \tau_{2}: 2.4 \mathrm{ps}(-0.157)\right.$, \\
D2A2 & $\left.\tau_{3}: 28.5 \mathrm{~ns}(0.528)\right]$ \\
& $460 \mathrm{~nm}\left[\tau_{1}: 0.12 \mathrm{ps}(0.770), \tau_{2}: 3.54 \mathrm{ps}(0.230)\right]$ \\
& $580 \mathrm{~nm}\left[\tau_{1}: 0.13 \mathrm{ps}(-0.162), \tau_{2}: 2.3 \mathrm{ps}(-0.173)\right.$, \\
& $\left.\tau_{3}: 42.09 \mathrm{~ns}(0.665)\right]$
\end{tabular}

${ }^{a}$ Data in parentheses are the fitted preexponential factors.

parameters for the early-time relaxation dynamics and population decay rates for $\mathbf{D} \mathbf{n} \mathbf{A} \boldsymbol{m}$ systems are listed in Table 3. In benzene, upon monitoring at short wavelengths of, e.g., $\sim 460 \mathrm{~nm}$, the relaxation dynamics of $\mathbf{D 2 A 1}$ obviously consist of a very fast decay of $\sim 430$ fs (component 1 ) and a relatively slow decay component of $\sim 2.2$ ps (component 2). Upon increasing the 
monitored wavelength the magnitudes (intensity at $t=0$ ) for both components gradually decrease. While the decay rate of component 1, within experimental error, remains unchanged, the decay of component 2 seems to be wavelength dependent. It requires at least two, and for some medium wavelengths even three, exponential terms to achieve good convoluted fits. For simplicity, Table 3 lists no more than two decay components. Upon increasing the monitored wavelength to the very red edge of, e.g., $580 \mathrm{~nm}$, both decay components 1 and 2 become the rise components, followed by a rather long population decay time of 28.5 ns. Obviously, the rise components of $430 \mathrm{fs}$ monitored at the charge transfer emission correlate well with the fast decay component (component 1) monitored at the locally emitted region.

To clearly map the above results, a temporal spectral evolution for the emission of D2A1 in benzene was reconstructed; the results are depicted in Figure 5. As shown in Figure 5, the time-dependent spectral evolution of D2A1 in benzene, acquired at an earlier time domain of, e.g., $500 \mathrm{fs}$, seems to consist of dual emission bands with peak wavelength at $<450$ and $460 \mathrm{~nm}$. Unfortunately, due to the spectral overlap with respect to the pump pulse the actual peak wavelength for the $<450$ band cannot be resolved. Nevertheless, the $<450 \mathrm{~nm}$ band can reasonably be ascribed to the $\mathbf{D 2}$ emission due to their similar emission wavelength. The $460 \mathrm{~nm}$ band gradually increases and shifts from 460 to $\sim 490 \mathrm{~nm}$ upon increasing the pump - probe delay time from 500 fs to $\sim 5$ ps, accompanied by the disappearance of the $<450 \mathrm{~nm}$ emission band. The results firmly support the precursor-sater type of reaction, i.e., the photoinduced electron transfer process. After $>5$ ps delay time, in which the solvent (benzene) relaxation is nearly complete, the spectra remain unchanged. Note that the resulting $490 \mathrm{~nm}$ peak, within experimental error, is identical with the peak wavelength of the steady-state charge transfer emission. Thus, the results unambiguously confirm the ultrafast PET ( $\sim 430 \mathrm{fs})$ in D2A1, followed by a solvent relaxation process, resulting in a time-dependent spectral evolution. Certainly, due to the similar time scale between PET and solvent relaxation, concurrent PET and solvent relaxation may take place. However, the differentiation cannot be resolved at this stage unless in solvents with rather slow relaxation rate. Unfortunately, high concentration of $\mathbf{D} \mathbf{n} \mathbf{A} \boldsymbol{m}$ is required for the fluorescence upconversion so that samples can only be prepared in benzene and toluene.

Similar relaxation dynamics was resolved for D1A1 (see Table 3), in which the rate of PET was extracted to be 410 $\mathrm{fs}^{-1}$. In contrast, the relaxation dynamics of D1A2 and D2A2, monitored at a very red side of the emission of, e.g., $580 \mathrm{~nm}$ for D2A2, were established by a response-limited $\left(>6.6 \times 10^{12}\right.$ $\left.\mathrm{s}^{-1}\right)$ rise and a fast but resolvable rise component $\left(\sim 4 \times 10^{11}\right.$ $\mathrm{s}^{-1}$ ) that correlated well with the solvent relaxation, then followed by a single-exponential population decay component of $\sim 2.4 \times 10^{8} \mathrm{~s}^{-1}$ (see Table 3). Thus, it seems that the rate of PET is dependent on the number of anchored acceptors. For the cases of D1A1 and D2A1 the PET rate was resolved to be $\sim 2.44 \times 10^{12}$ and $2.32 \times 10^{12} \mathrm{~s}^{-1}$, respectively, which, within experimental errors, can be considered to be identical. Conversely, the rate is beyond the system response of $6.6 \times 10^{12}$ $\mathrm{s}^{-1}$ for D1A2 and D2A2 possessing dual accessible acceptors. Statistically, based on the random access for an electron-transfer process the PET rate is expected to be double with respect to that of D2A1 composites. For further verification, more rigorous examination has to be performed on other $\mathbf{D} \mathbf{n} \mathbf{A} \boldsymbol{m}$ systems such as D1A3 and D3A1. Unfortunately, limited by synthetic pathway as well as system response, this approach is not feasible at the current stage.

\section{Conclusion}

In conclusion, we have designed and synthesized a series of 9,9'-spirobifluorene-bridged bipolar compounds DnAm bearing various $n: m$ ratios for triarylamine (D) versus 1,3,4-oxadiazoleconjugated oligoaryl moiety (A) to investigate the corresponding photoinduced electron-transfer property. Via cyclic voltammetry and absorption/emission spectra, the PET process has been proven to be exergonic. The excitation behaviors were probed by steady-state solvatochromism and femtosecond fluorescence up-conversion spectroscopy. The rate of PET is dependent on the number of anchored acceptors and is resolved to be $\sim 2.44 \times 10^{12}$ and $2.32 \times 10^{12} \mathrm{~s}^{-1}$ for D2A1 and D1A1, respectively. The overall reaction dynamics can be rationalized by an ultrafast rate of PET followed by the solvent relaxation process, resulting in a solvent-polarity dependent emission. The remarkable PET process may lead to the feasibility of finetuning the D/A strength as well as the number of spirobifluorene conjugation, so that the flow of electrons can be precisely regulated. Such a conceptual design may be advantageously exploited in, e.g., photovoltaic devices, in which the electron transfer can be greatly extended. To achieve this goal, focus on poly-spirobifluorene conjugated bipolar or triad systems is currently in progress.

\section{Experimental Section}

Synthesis of 2,7-Dicyano-9,9' -spirobifluorene (1). The mixture of 2,7-dibromo-9,9'-spirobifluorene (1.88 g, $4.0 \mathrm{mmol})$ and copper cyanide $(1.43 \mathrm{~g}, 16.0 \mathrm{mmol})$ in dry DMF $(16 \mathrm{~mL})$ was refluxed for $8 \mathrm{~h}$. The cooled reaction mixture was added with a solution of $\mathrm{HCl}(4 \mathrm{~mL}, 12 \mathrm{~N}), \mathrm{FeCl}_{3}(7.0 \mathrm{~g})$, and water $(40 \mathrm{~mL})$. Then the mixture was heated for $0.5 \mathrm{~h}$ at $70{ }^{\circ} \mathrm{C}$. After the reaction was complete, the mixture was extracted with toluene three times. Recrystallization from $\mathrm{CHCl}_{3}$ and methanol gave pure compound 1 (1.3 g, 90\%). Mp 271-272 ${ }^{\circ} \mathrm{C}$; IR (KBr) v 3445, 2229, 1647, $1636,1560,1541,727,741,642,654,620 \mathrm{~cm}^{-1} ;{ }^{1} \mathrm{H} \mathrm{NMR}\left(\mathrm{CDCl}_{3}\right.$, $400 \mathrm{MHz}) \delta 8.00(\mathrm{~d}, J=8.0 \mathrm{~Hz}, 2 \mathrm{H}), 7.90(\mathrm{~d}, J=7.7 \mathrm{~Hz}, 2 \mathrm{H})$, $7.73(\mathrm{dd}, J=8.0,1.4 \mathrm{~Hz}, 2 \mathrm{H}), 7.46(\mathrm{dt}, J=7.5,0.9 \mathrm{~Hz}, 2 \mathrm{H}), 7.17$ $(\mathrm{dt}, J=7.5,0.9 \mathrm{~Hz}, 2 \mathrm{H}), 7.07(\mathrm{~s}, 2 \mathrm{H}), 6.67(\mathrm{~d}, J=7.7 \mathrm{~Hz}, 2 \mathrm{H})$; ${ }^{13} \mathrm{C} \mathrm{NMR}\left(\mathrm{CDCl}_{3}, 100 \mathrm{MHz}\right) \delta 150.4,145.4,143.9,141.8,132.3$, 128.9, 128.4, 128.1, 123.9, 121.7, 120.7, 118.4, 112.7, 65.6; MS $\left(\mathrm{m} / \mathrm{z}, \mathrm{FAB}^{+}\right) 366(10), 154$ (100); HRMS $\left(\mathrm{FAB}^{+}\right)$calcd for $\mathrm{C}_{27} \mathrm{H}_{14} \mathrm{~N}_{2}$ 366.1157, found 366.1157. Anal. Calcd for $\mathrm{C}_{27} \mathrm{H}_{14} \mathrm{~N}_{2}$ : C, 88.50; H, 3.85; N, 7.65. Found: C, 88.45; H, 4.00; N, 7.55.

Synthesis of 2,7-Dibromo-2', $7^{\prime}$-dicyano-9,9'-spirobifluorene (2b). Bromine $(3.1 \mathrm{~mL}, 60 \mathrm{mmol})$ was added slowly to a mixture of 2,7-dicyano-9,9'-spriobifluorene (1) (5.26 g, $15 \mathrm{mmol})$ and $\mathrm{FeCl}_{3}$ (122 mg, $0.75 \mathrm{mmol}$ ) in $50 \mathrm{~mL}$ of $\mathrm{CH}_{2} \mathrm{Cl}_{2}$ at reflux. After being heated for $24 \mathrm{~h}$, the mixture was quenched with $\mathrm{Na}_{2} \mathrm{CO}_{3(\mathrm{aq})}(20$ $\mathrm{mL}$ ) and extracted with $\mathrm{CH}_{2} \mathrm{Cl}_{2}$. The crude material was purified by recrystallization from $\mathrm{CH}_{2} \mathrm{Cl}_{2}$ and hexane to give compound 2b $\left(6.83 \mathrm{~g}, 87 \%\right.$ yield). Mp 364-366 ${ }^{\circ} \mathrm{C}$; IR (KBr) $v 2223,1600$, 1566, 1454, 1313, 1248, 1208, 1056, 950, $797 \mathrm{~cm}^{-1} ;{ }^{1} \mathrm{H}$ NMR $\left(\mathrm{CDCl}_{3}, 400 \mathrm{MHz}\right) \delta 8.00(\mathrm{~d}, J=8.0 \mathrm{~Hz}, 2 \mathrm{H}), 7.77(\mathrm{dd}, J=8.0$, $1.6 \mathrm{~Hz}, 2 \mathrm{H}), 7.73(\mathrm{~d}, J=8.4 \mathrm{~Hz}, 2 \mathrm{H}), 7.58(\mathrm{dd}, J=8.4,2.0 \mathrm{~Hz}$, 2H) $7.05(\mathrm{~m}, 2 \mathrm{H}), 6.76(\mathrm{~d}, J=1.6 \mathrm{~Hz}, 2 \mathrm{H}) ;{ }^{13} \mathrm{C} \mathrm{NMR}\left(\mathrm{CDCl}_{3}\right.$, $100 \mathrm{MHz}) \delta 148.5,146.9,143.6,139.5,132.8,132.2,127.9,126.8$, $122.3,121.9,121.8,118.0,113.0,65.1 ; \mathrm{MS}\left(\mathrm{m} / \mathrm{z}, \mathrm{FAB}^{+}\right) 523.9$ (20), 521.9 (10), 307.0 (100); HRMS ( $\mathrm{FAB}^{+}$) calcd for $\mathrm{C}_{27} \mathrm{H}_{12^{-}}$ ${ }^{81} \mathrm{Br}^{81} \mathrm{BrN}_{2}$ 525.9326, found 525.9352; calcd for $\mathrm{C}_{27} \mathrm{H}_{12}{ }^{81} \mathrm{Br}^{79} \mathrm{BrN}_{2}$ 523.9347, found 523.9351; calcd for $\mathrm{C}_{27} \mathrm{H}_{12}{ }^{79} \mathrm{Br}^{79} \mathrm{BrN}_{2}$ 521.9367, found 521.9357 . 
Synthesis of 2,7-Dicyano-2' -diphenylamino-9,9'-spirobifluorene (3a). Bromine $(0.75 \mathrm{~mL}, 15 \mathrm{mmol})$ was added slowly to a mixture of 2,7-dicyano-9, $9^{\prime}$-spriobifluorene (5.26 g, $15 \mathrm{mmol}$ ) and $\mathrm{FeCl}_{3}(122 \mathrm{mg}, 0.75 \mathrm{mmol})$ in $50 \mathrm{~mL}$ of $\mathrm{CH}_{2} \mathrm{Cl}_{2}$ at reflux. After being heated for $8 \mathrm{~h}$, the mixture was quenched with sodium bicarbonate and extracted with $\mathrm{CH}_{2} \mathrm{Cl}_{2}$. The solvent was removed under vacuum. The crude compound was used in the next step without further purification. The mixture of diphenylamine (5.41 $\mathrm{g}, 32 \mathrm{mmol}), \mathrm{Pd}(\mathrm{OAc})_{2}$ (45 mg, $\left.0.2 \mathrm{mmol}\right)$, tri-tert-butylphosphine ( $7.6 \mathrm{~mL}, 0.05 \mathrm{M}$ in toluene), sodium tert-butoxide ( $2.3 \mathrm{~g}, 24 \mathrm{mmol})$, and the crude brominated compound was dissolved in dry toluene $(30 \mathrm{~mL})$ and refluxed for $8 \mathrm{~h}$. It was then extracted with $\mathrm{CH}_{2} \mathrm{Cl}_{2}$, the organic layer was washed with water and dried over $\mathrm{MgSO}_{4}$, and the solvent was evaporated in a vacuum. Column chromatography of the crude mixture on silica gel (EtOAc/hexanes $=1 / 10)$ gave 3a (3.27 g, 49\% yield) as a yellow solid. Mp 262-264 ${ }^{\circ} \mathrm{C}$; IR $(\mathrm{KBr}) v 3045,2223,1600,1500,1447,1407,1268,824,751$, $698 \mathrm{~cm}^{-1} ;{ }^{1} \mathrm{H}$ NMR $\left(\mathrm{CDCl}_{3}, 400 \mathrm{MHz}\right) \delta 8.01(\mathrm{~d}, J=7.6 \mathrm{~Hz}$, 2H), $7.89(\mathrm{~d}, J=7.6 \mathrm{~Hz}, 1 \mathrm{H}), 7.84-7.79(\mathrm{~m}, 3 \mathrm{H}), 7.52(\mathrm{t}, J=8.0$ $\mathrm{Hz}, 1 \mathrm{H}), 7.38(\mathrm{~s}, 1 \mathrm{H}), 7.29-7.26(\mathrm{~m}, 4 \mathrm{H}), 7.22-7.19(\mathrm{~m}, 3 \mathrm{H})$, 7.09-7.05 (m, 6H), $6.70(\mathrm{~d}, J=7.6 \mathrm{~Hz}, 1 \mathrm{H}), 6.53(\mathrm{~s}, 1 \mathrm{H}) ;{ }^{13} \mathrm{C}$ $\mathrm{NMR}\left(\mathrm{CDCl}_{3}, 100 \mathrm{MHz}\right) \delta 150.2,148.1,147.1,146.4,145.0,143.6$, 141.4, 136.0, 132.1, 129.0, 128.7, 127.8, 127.2, 124.2, 124.0, 123.3, $122.9,121.6,121.2,119.9,118.6,118.4,112.4 ; \mathrm{MS}\left(\mathrm{m} / \mathrm{z}, \mathrm{FAB}^{+}\right)$ 533.2 (40), 307.0 (100); HRMS calcd for $\mathrm{C}_{38} \mathrm{H}_{23} \mathrm{~N}_{3}$ 533.1892, found 533.1890 .

Synthesis of 2,7-Dicyano-2', $7^{\prime}$-bis(diphenylamino)-9,9'-spirobifluorene (3b). The mixture of 2,7-dibromo-2', $7^{\prime}$-dicyano-9, $9^{\prime}$ spirobifluorene (2b) (4.1 g, $8.0 \mathrm{mmol})$, diphenylamine (5.4 g, 32 mmol), $\mathrm{Pd}(\mathrm{OAc})_{2}$ (45 mg, $0.2 \mathrm{mmol}$ ), tri-tert-butylphosphine (7.6 $\mathrm{mL}, 0.05 \mathrm{M}$ in toluene), and sodium tert-butoxide ( $2.3 \mathrm{~g}, 24 \mathrm{mmol})$ in dry toluene $(20 \mathrm{~mL})$ was refluxed for $8 \mathrm{~h}$. The mixture was extracted with $\mathrm{CH}_{2} \mathrm{Cl}_{2}$ and the organic layer was washed with water and dried over $\mathrm{MgSO}_{4}$, followed by evaporation of solvent. The crude product was purified by column chromatography on silica gel $($ EtOAc/hexanes $=1 / 7)$ to give $\mathbf{3 b}$ as a yellow solid $(1.68 \mathrm{~g}$, $75 \%$ yield). Mp 327-328 ${ }^{\circ} \mathrm{C}$; IR (KBr) v 3063, 3038, 2364, 2345, 2230, 1594, 1468, 1272, 821, 754, $696 \mathrm{~cm}^{-1} ;{ }^{1} \mathrm{H} \mathrm{NMR}\left(\mathrm{CDCl}_{3}\right.$, $400 \mathrm{MHz}) \delta 7.82(\mathrm{~d}, J=8.0 \mathrm{~Hz}, 2 \mathrm{H}), 7.66(\mathrm{dd}, J=8.0,1.4 \mathrm{~Hz}$, $2 \mathrm{H}), 7.62(\mathrm{~d}, J=8.3 \mathrm{~Hz}, 2 \mathrm{H}), 7.23(\mathrm{~d}, J=0.7 \mathrm{~Hz}, 2 \mathrm{H}), 7.18-$ $7.14(\mathrm{~m}, 8 \mathrm{H}), 7.06(\mathrm{dd}, J=8.3,2.0 \mathrm{~Hz}, 2 \mathrm{H}), 6.97-6.93(\mathrm{~m}, 12 \mathrm{H})$, $6.37(\mathrm{~d}, J=2.0 \mathrm{~Hz}, 2 \mathrm{H}) ;{ }^{13} \mathrm{C} \mathrm{NMR}\left(\mathrm{CDCl}_{3}, 100 \mathrm{MHz}\right) \delta 150.4$, 147.4, 147.3, 146.6, 143.8, 136.2, 132.2, 129.1, 127.8, 124.6, 123.9, $122.9,121.9,120.6,118.9,118.6,112.4,65.4 ; \mathrm{MS}\left(\mathrm{m} / \mathrm{z}, \mathrm{FAB}^{+}\right)$ 700 (50), 613 (5), 533 (5), 460 (20), 391 (10), 307 (100); HRMS calcd for $\mathrm{C}_{51} \mathrm{H}_{32} \mathrm{~N}_{4} 700.2627$, found 700.2624.

Synthesis of D1A2. The mixture of 2,7-dicyano-2'-diphenylamino-9, ' $^{\prime}$-spirobifluorene (3a) $(1.07 \mathrm{~g}, 2.0 \mathrm{mmol})$, sodium azide (286 mg, $4.4 \mathrm{mmol})$, and ammonium chloride (246 mg, $4.4 \mathrm{mmol})$ in DMF $(10 \mathrm{~mL})$ was heated at $100{ }^{\circ} \mathrm{C}$ for $24 \mathrm{~h}$. The reaction was quenched by adding $10 \% \mathrm{HCl}$ solution $(10 \mathrm{~mL})$. The resulting precipitate was collected by filtration and dried in a vacuum. The crude compound was used in the next step without further purification. The mixture of the crude tetrazole compound and 4-tert-butylbenzoyl chloride $(980 \mathrm{mg}, 5.0 \mathrm{mmol})$ in dry pyridine $(10 \mathrm{~mL})$ was refluxed for $8 \mathrm{~h}$. Then the mixture was quenched with dilute $\mathrm{HCl}(10 \mathrm{~mL})$ and extracted with $\mathrm{CH}_{2} \mathrm{Cl}_{2}$. The organic layer was washed with water and dried over $\mathrm{MgSO}_{4}$, and the solvent was evaporated to dryness. Purification of D1A2 was accomplished by using column chromatography (EtOAc/ hexanes $=1 / 8)$ on silica gel and HPLC (EtOAc/hexanes $=2 / 3)$ to obtain a yellow solid (601 mg, 34\%). Mp $273{ }^{\circ} \mathrm{C}$ (DSC); IR (KBr) v 3051, 2965, 2872, $1613,1600,1493,1447,1281,1116,1069,850,731,698 \mathrm{~cm}^{-1}$; ${ }^{1} \mathrm{H} \mathrm{NMR}\left(\mathrm{CDCl}_{3}, 400 \mathrm{MHz}\right) \delta 8.18(\mathrm{dd}, J=8.0,1.6 \mathrm{~Hz}, 2 \mathrm{H})$, $8.041(\mathrm{dt}, J=8.8,2.0 \mathrm{~Hz}, 4 \mathrm{H}), 7.97(\mathrm{~d}, J=7.6 \mathrm{~Hz}, 2 \mathrm{H}), 7.82(\mathrm{~d}$, $J=7.6 \mathrm{~Hz}, 1 \mathrm{H}), 7.76(\mathrm{~d}, J=8.8 \mathrm{~Hz}, 1 \mathrm{H}), 7.61(\mathrm{t}, J=0.8 \mathrm{~Hz}$, $2 \mathrm{H}), 7.53(\mathrm{dt}, J=8.4,2.0 \mathrm{~Hz}, 4 \mathrm{H}), 7.39(\mathrm{td}, J=7.6,1.2 \mathrm{~Hz}, 1 \mathrm{H})$, $7.09-7.05(\mathrm{~m}, 6 \mathrm{H}), 6.96(\mathrm{dd}, J=3.2,1.6 \mathrm{~Hz}, 4 \mathrm{H}), 6.89-6.85(\mathrm{~m}$, $2 \mathrm{H}), 6.69(\mathrm{~d}, J=7.6 \mathrm{~Hz}, 1 \mathrm{H}), 6.55(\mathrm{~d}, J=2.0 \mathrm{~Hz}, 1 \mathrm{H}), 1.38-$ $1.35(\mathrm{~m}, 18 \mathrm{H}) ;{ }^{13} \mathrm{C} \mathrm{NMR}\left(\mathrm{CDCl}_{3}, 100 \mathrm{MHz}\right) \delta 164.0,163.6,154.8$, 150.0, 147.5, 147.4, 146.8, 146.1, 143.1, 141.3, 136.2, 128.6, 127.9, 126.8, 126.6, 126.4, 125.6, 123.7, 123.6, 123.3, 122.4, 122.2, 121.0, $120.8,120.5,119.5,118.8,65.9,35.3,31.4$; MS $\left(m / z, \mathrm{FAB}^{+}\right) 884.4$ (100), 883.4 (80); HRMS calcd for $\mathrm{C}_{61} \mathrm{H}_{49} \mathrm{~N}_{5} \mathrm{O}_{2} 883.3886$, found 883.3892.

Synthesis of 2,7-Bis(diphenylamino)-2', $7^{\prime}$-di(1H-tetrazol-5-yl)9,9'-spirobifluorene (4b). The mixture of 2,7-dicyano-2', $7^{\prime}$-bis(diphenylamino)-9,9'-spirobifluorene (3b) (1.40 g, $2.0 \mathrm{mmol}$ ), sodium azide ( $286 \mathrm{mg}, 4.4 \mathrm{mmol}$ ), and ammonium chloride (246 $\mathrm{mg}, 4.4 \mathrm{mmol}$ ) in DMF was heated at $100{ }^{\circ} \mathrm{C}$ for $24 \mathrm{~h}$. Then the reaction was quenched by adding dilute $\mathrm{HCl}(10 \mathrm{~mL})$. The resulting precipitate was collected by filtration and recrystallized from ethanol to gave compound $\mathbf{4 b}\left(1.26 \mathrm{~g}, 80 \%\right.$ yield). Mp $227-228{ }^{\circ} \mathrm{C}$; IR $(\mathrm{KBr}) v 3423,2370,2337,2114,1652,1635,1483,1273,1240$, 737, 751, 695, 543, $504 \mathrm{~cm}^{-1} ;{ }^{1} \mathrm{H}$ NMR (DMSO- $\left.d_{6}, 400 \mathrm{MHz}\right) \delta$ $8.14(\mathrm{~d}, J=7.7 \mathrm{~Hz}, 2 \mathrm{H}), 8.12(\mathrm{~d}, J=8.0 \mathrm{~Hz}, 2 \mathrm{H}), 7.90(\mathrm{~d}, J=$ $8.3 \mathrm{~Hz}, 2 \mathrm{H}), 7.52(\mathrm{~s}, 2 \mathrm{H}), 7.05(\mathrm{t}, J=7.5 \mathrm{~Hz}, 8 \mathrm{H}), 6.88(\mathrm{~d}, J=$ $7.3 \mathrm{~Hz}, 4 \mathrm{H}), 6.82(\mathrm{dd}, J=8.4,0.8 \mathrm{~Hz}, 8 \mathrm{H}), 6.26(\mathrm{~s}, 2 \mathrm{H}) ;{ }^{13} \mathrm{C}$ (DMSO- $\left.d_{6}, 100 \mathrm{MHz}\right) \delta 148.9,147.3,145.9,141.7,135.2,128.6$, 123.0, 122.4, 121.7, 121.3, 120.5, 117.7, 65.0; $\mathrm{MS}\left(\mathrm{m} / \mathrm{z}, \mathrm{FAB}^{+}\right)$ 786 (100), 715 (60), 700 (40); HRMS calcd for $\mathrm{C}_{51} \mathrm{H}_{34} \mathrm{~N}_{10} 786.2968$, found 786.2964 .

Synthesis of D2A2. The mixture of compound $4 \mathbf{b}$ (1.18 g, 1.5 $\mathrm{mmol}$ ) and 4-tert-butylbenzoyl chloride $(784 \mathrm{mg}, 4.0 \mathrm{mmol})$ in dry pyridine $(5 \mathrm{~mL})$ was refluxed for $8 \mathrm{~h}$. Then the mixture was quenched with dilute $\mathrm{HCl}(10 \mathrm{~mL})$, extracted with $\mathrm{CH}_{2} \mathrm{Cl}_{2}$, and dried with $\mathrm{MgSO}_{4}$. The solution was then concentrated by rotary evaporation. Column chromatography of the crude mixture on silica gel $($ EtOAc/hexanes $=1 / 3)$ gave D2A2 as a yellow solid $(1.14 \mathrm{~g}$, $73 \%$ yield). IR (KBr) $v$ 3444, 2696, 2108, 1637, 1495, 1468, 1314, 1271, 751, 728, 697, $504 \mathrm{~cm}^{-1} ;{ }^{1} \mathrm{H} \mathrm{NMR}\left(\mathrm{CDCl}_{3}, 400 \mathrm{MHz}\right) \delta$ $8.11(\mathrm{dd}, J=8.0,1.5 \mathrm{~Hz}, 2 \mathrm{H}), 8.08(\mathrm{dd}, J=6.7,1.9 \mathrm{~Hz}, 4 \mathrm{H})$, $7.88(\mathrm{~d}, J=8.0 \mathrm{~Hz}, 2 \mathrm{H}), 7.73(\mathrm{~d}, J=1.0 \mathrm{~Hz}, 2 \mathrm{H}), 7.68(\mathrm{~d}, J=$ $8.3 \mathrm{~Hz}, 2 \mathrm{H}), 7.57(\mathrm{dd}, J=6.7,1.9 \mathrm{~Hz}, 4 \mathrm{H}), 7.09-7.05(\mathrm{~m}, 10 \mathrm{H})$, $6.95(\mathrm{~d}, J=7.6 \mathrm{~Hz}, 8 \mathrm{H}), 6.87(\mathrm{t}, J=7.2 \mathrm{~Hz}, 4 \mathrm{H}), 6.51(\mathrm{~d}, J=1.9$ $\mathrm{Hz}, 2 \mathrm{H}), 1.39(\mathrm{~s}, 18 \mathrm{H}) ;{ }^{13} \mathrm{C}$ NMR $\left(\mathrm{CDCl}_{3}, 100 \mathrm{MHz}\right) \delta 164.7$, $164.4,155.5,150.6,148.1,147.5,147.2,143.6,136.6,129.1,126.9$, 126.1, 124.4, 123.9, 122.6, 122.5, 121.4, 121.0, 120.5, 119.4, 77.2, 35.1, 31.1; MS (m/z, $\left.\mathrm{FAB}^{+}\right) 1051$ (100), 875 (20), 849 (10), 716 (10); HRMS calcd for $\mathrm{C}_{73} \mathrm{H}_{58} \mathrm{~N}_{6} \mathrm{O}_{2} 1050.4621$, found 1050.4657 , 1051.4692. Anal. Calcd for $\mathrm{C}_{73} \mathrm{H}_{58} \mathrm{~N}_{6} \mathrm{O}_{2}: \mathrm{C}, 83.40 ; \mathrm{H}, 5.56 ; \mathrm{N}$, 7.99. Found: C, 83.11; H, 5.80; N, 8.0.

Synthesis of 2-Bromo-2'-methyl-9,9'-spirobifluorene (5a). Arylmagnesium iodide was first prepared in advance from 2-iodo4'-methylbiphenyl (4.41 g, $15 \mathrm{mmol}$ ) and magnesium (360 mg, 15 $\mathrm{mmol}$ ) in dry ether. Then arylmagesium iodide was added into the flask containing 2-bromofluoreneone $(10 \mathrm{mmol})$ in THF $(50 \mathrm{~mL})$. The mixture was refluxed for $8 \mathrm{~h}$, and then quenched with water, then it was extracted with EtOAc and dried with $\mathrm{MgSO}_{4}$. The organic solution was then concentrated by rotary evaporation. The crude product was dissolved in acetic acid $(100 \mathrm{~mL})$ and concentrated $\mathrm{HCl}(4 \mathrm{~mL}, 12.0 \mathrm{~N})$ was added dropwise. After the solution was heated for $1 \mathrm{~h}$, the precipitate was collected by filtration to give pure compound 5a ( $2.86 \mathrm{~g}, 70 \%$ yield). Mp $240-242{ }^{\circ} \mathrm{C}$; IR $(\mathrm{KBr}) v 3032,2919,1606,1440,1407,1056,824,731 \mathrm{~cm}^{-1} ;{ }^{1} \mathrm{H}$ NMR $\left(\mathrm{CDCl}_{3}, 400 \mathrm{MHz}\right) \delta 7.83-7.80(\mathrm{~m}, 2 \mathrm{H}), 7.74-7.70(\mathrm{~m}$, 2H), $7.49(\mathrm{dd}, J=8.8 \mathrm{~Hz}, 2.0 \mathrm{~Hz}, 1 \mathrm{H}), 7.39-7.34(\mathrm{~m}, 2 \mathrm{H}), 7.20$ (dt, $J=7.6,0.8 \mathrm{~Hz}, 1 \mathrm{H}), 7.16-7.07(\mathrm{~m}, 2 \mathrm{H}), 6.87(\mathrm{~d}, J=2.0 \mathrm{~Hz}$, $1 \mathrm{H}), 6.75-6.69(\mathrm{~m}, 2 \mathrm{H}), 6.53(\mathrm{~s}, 1 \mathrm{H}), 2.22(\mathrm{~s}, 3 \mathrm{H}) ;{ }^{13} \mathrm{C} \mathrm{NMR}$ $\left(\mathrm{CDCl}_{3}, 100 \mathrm{MHz}\right) \delta 150.8,148.5,147.8,147.5,141.6,140.5$, $140.4,138.9$, 137.8, 130.6, 128.7, 128.0, 127.7, 127.6, 127.2, 127.1, 124.4, 124.0, 123.8, 121.2, 121.1, 119.8, 119.7, 119.6, 65.6, 21.6; MS ( $\left.m / z, \mathrm{FAB}^{+}\right) 410.0$ (50), 307.0 (100) 154.0 (100); HRMS calcd for $\mathrm{C}_{26} \mathrm{H}_{17}{ }^{81} \mathrm{Br}$ 410.0493, found 410.0492, HRMS calcd for $\mathrm{C}_{26} \mathrm{H}_{17}{ }^{79} \mathrm{Br} 408.0514$, found 408.0510.

Synthesis of 2,7-Dibromo-2'-methyl-9, $9^{\prime}$-spirobifluorene (5b). Grignard reagent prepared in advance from 2-iodo-4'-methylbiphenyl (4.41 g, $15 \mathrm{mmol}$ ) and magnesium (360 mg, $15 \mathrm{mmol})$ in 
dry ether was added into a solution containing 2,7-dibrmofluoreneone $(3.36 \mathrm{~g}, 10 \mathrm{mmol})$ in THF $(50 \mathrm{~mL})$. The mixture was refluxed for $8 \mathrm{~h}$, and then quenched with water. The mixture was extracted with EtOAc and dried over $\mathrm{MgSO}_{4}$. The organic solution was then concentrated by rotary evaporation. The crude mixture was dissolved in acetic acid $(100 \mathrm{~mL})$, and then concentrated $\mathrm{HCl}$ $(4 \mathrm{~mL}, 12.0 \mathrm{~N})$ was added dropwise. After the solution was heated for $1 \mathrm{~h}$, the precipitate was collected by filtration to give pure compound $\mathbf{5 b}$ ( $3.6 \mathrm{~g}, 74 \%$ yield). Mp $319-322{ }^{\circ} \mathrm{C}$; IR (KBr)1739, $1686,1447,1401,1255,1162,1056,824,685 ;{ }^{1} \mathrm{H} \mathrm{NMR}\left(\mathrm{CDCl}_{3}\right.$, $400 \mathrm{MHz}) \delta 7.80(\mathrm{~d}, J=8.2 \mathrm{~Hz}, 1 \mathrm{H}), 7.72(\mathrm{~d}, J=7.6 \mathrm{~Hz}, 1 \mathrm{H})$, $7.67(\mathrm{~d}, J=8.2 \mathrm{~Hz}, 2 \mathrm{H}), 7.49(\mathrm{dd}, J=8.2,2.0 \mathrm{~Hz}, 2 \mathrm{H}), 7.38(\mathrm{td}$, $J=7.6,1.0 \mathrm{~Hz}, 1 \mathrm{H}), 7.20(\mathrm{dd}, J=7.6,0.8 \mathrm{~Hz}, 1 \mathrm{H}), 7.11(\mathrm{td}, J=$ 7.6, $0.8 \mathrm{~Hz}, 1 \mathrm{H}), 6.85(\mathrm{~d}, J=2 \mathrm{~Hz}, 2 \mathrm{H}), 6.69$ (d, $J=7.6 \mathrm{~Hz}, 1 \mathrm{H})$, $6.51(\mathrm{~d}, J=0.8 \mathrm{~Hz}, 1 \mathrm{H}), 2.24(\mathrm{~s}, 3 \mathrm{H}) ;{ }^{13} \mathrm{C} \mathrm{NMR}\left(\mathrm{CDCl}_{3}, 100\right.$ MHz) $\delta 150.90,147.31,147.03,141.95,139.73,139.18,138.30$, $131.21,129.33,128.37,127.72,127.55,124.77,124.13,122.04$, 121.51, 120.18, 120.11, 65.80, 21.92; MS (FAB $\left.{ }^{+}, \mathrm{m} / \mathrm{z}\right) 485$ (35); HRMS calcd for $\mathrm{C}_{26} \mathrm{H}_{16}{ }^{81} \mathrm{Br}^{81} \mathrm{Br} 489.9578$, found 489.9604, HRMS calcd for $\mathrm{C}_{26} \mathrm{H}_{16}{ }^{79} \mathrm{Br}^{81} \mathrm{Br}$ 487.9598, found 487.9612, HRMS calcd for $\mathrm{C}_{26} \mathrm{H}_{16}{ }^{79} \mathrm{Br}^{79} \mathrm{Br} 485.9619$, found 485.9612 .

Synthesis of 2-Bromo-2' -carboxyl-9,9'-spirobifluorene (6a). 2-Bromo-2'-methyl-9, $9^{\prime}$-spirobifluorene (5a) (1.63 g, $4 \mathrm{mmol}$ ) was dissolved in benzene $(15 \mathrm{~mL})$ and acetic acid $(15 \mathrm{~mL})$. A solution of chromium oxide ( $4.0 \mathrm{~g}, 40 \mathrm{mmol})$, acetic acid $(5 \mathrm{~mL})$, and water $(10 \mathrm{~mL})$ was added slowly at reflux. After being heated for $8 \mathrm{~h}$, the mixture was quenched with water and extracted with EtOAc. The solvent was then removed in a vacuum and the crude product was purified by recrystallization from $\mathrm{CHCl}_{3}$ and methanol to give pure compound 6a (1.09 g, 62\% yield). Mp $360{ }^{\circ} \mathrm{C}$ (DSC); IR (KBr) $v$ 3436, 3032, 2355, 2329, 1686, 1619, 1295, $758 \mathrm{~cm}^{-1} ;{ }^{1} \mathrm{H}$ NMR (acetone- $\left.d_{6}, 400 \mathrm{MHz}\right) \delta 8.14-8.11(\mathrm{~m}, 3 \mathrm{H}), 8.04(\mathrm{~d}, J=7.6 \mathrm{~Hz}$, $1 \mathrm{H}), 7.99(\mathrm{~d}, J=8.0 \mathrm{~Hz}, 1 \mathrm{H}), 7.61(\mathrm{dd}, J=8.0,1.6 \mathrm{~Hz}, 1 \mathrm{H})$, $7.51-7.43(\mathrm{~m}, 2 \mathrm{H}), 7.34(\mathrm{~s}, 1 \mathrm{H}), 7.27(\mathrm{t}, J=7.6 \mathrm{~Hz}, 1 \mathrm{H}), 7.21(\mathrm{t}$, $J=7.6 \mathrm{~Hz}, 1 \mathrm{H}), 6.84(\mathrm{~d}, J=1.6 \mathrm{~Hz}, 1 \mathrm{H}), 6.77(\mathrm{~d}, J=7.2 \mathrm{~Hz}$, $1 \mathrm{H}), 6.71(\mathrm{~d}, J=7.6 \mathrm{~Hz}, 1 \mathrm{H}) ;{ }^{13} \mathrm{C}$ NMR (DMSO- $\left.d_{6}, 100 \mathrm{MHz}\right) \delta$ 166.0, 149.0, 147.4, 147.0, 146.4, 145.0, 140.0, 139.5, 130.7, 129.6, $129.2,128.8,128.1,128.0,127.9,127.6,125.5,123.4,123.1,122.9$, 122.2, 121.2, 120.5, 120.4, 120.2, 65.0; $\mathrm{MS}\left(\mathrm{m} / \mathrm{z}, \mathrm{FAB}^{+}\right) 307.0$ (30), 154.0 (100); HRMS calcd for $\mathrm{C}_{26} \mathrm{H}_{15}{ }^{81} \mathrm{BrO}_{2} 440.0235$, found 440.0269, HRMS calcd for $\mathrm{C}_{26} \mathrm{H}_{15}{ }^{79} \mathrm{BrO}_{2} 438.0255$, found 438.0281.

Synthesis of 2,7-Dibromo-2' -carboxyl-9,9' -spirobifluorene (6b). 2,7-Dibromo-2'-methyl-9,9'-spirobifluorene (5b) $(2.3 \mathrm{~g}, 4.7 \mathrm{mmol})$ was dissolved in benzene $(35 \mathrm{~mL})$ and acetic acid $(30 \mathrm{~mL})$, which was slowly added to a solution of chromium oxide (2.3 g, 23.5 $\mathrm{mmol})$, acetic acid $(5 \mathrm{~mL})$, and water $(10 \mathrm{~mL})$ at reflux. After being heated for $8 \mathrm{~h}$, the mixture was quenched with water, and extracted with EtOAc. The solvent was removed in a vacuum and the crude product was purified by recrystallization from $\mathrm{CHCl}_{3}$ and methanol to give pure compound $\mathbf{6 b}(1.8 \mathrm{~g}, 76 \%$ yield $) . \mathrm{Mp} 375-377{ }^{\circ} \mathrm{C}$; IR $(\mathrm{KBr}) v 3450,1778,1707,1270,1207,971 \mathrm{~cm}^{-1} ;{ }^{1} \mathrm{H}$ NMR (DMSO- $\left.d_{6}, 400 \mathrm{MHz}\right) \delta 8.14(\mathrm{dd}, J=11.6,8 \mathrm{~Hz}, 2 \mathrm{H}), 8.06-8.02$ $(\mathrm{m}, 3 \mathrm{H}), 7.64(\mathrm{dd}, J=8.0,1.8 \mathrm{~Hz}, 2 \mathrm{H}), 7.49(\mathrm{t}, J=7.6 \mathrm{~Hz}, 1 \mathrm{H})$, 7.26-7.10 (m, 2H), 6.75-6.72 (m, 3H); MS (EI, $m / z)$ 156(15). ${ }^{13} \mathrm{C}$ NMR (DMSO- $\left.d_{6}, 100 \mathrm{MHz}\right) \delta 165.8,148.6,146.6,146.0$, 144.9, 139.4, 138.8, 130.8, 129.6, 128.8, 128.1, 125.5, 123.2, 123.0, 122.4, 121.2, 120.7, 120.4, 64.7; MS ( $\left./ \mathrm{z} / \mathrm{FAB}^{+}\right) 517.9$ (20), 307.0 (100); HRMS calcd for $\mathrm{C}_{25} \mathrm{H}_{14}{ }^{81} \mathrm{Br}^{81} \mathrm{BrO}_{2}$ 519.9320, found 519.9359, HRMS calcd for $\mathrm{C}_{25} \mathrm{H}_{14}{ }^{79} \mathrm{Br}^{81} \mathrm{BrO}_{2}$ 517.9340, found 517.9376, HRMS calcd for $\mathrm{C}_{25} \mathrm{H}_{14}{ }^{79} \mathrm{Br}^{79} \mathrm{BrO}_{2}$ 515.9361, found 515.9362.

Synthesis of 2-Bromo-2'-(4-tert-butylphenyl-1H-tetrazole-5yl)-9,9'-spirobifluorene (7a). Compound $\mathbf{6 a}(518 \mathrm{mg}, 1 \mathrm{mmol})$ in thionyl chloride $(10 \mathrm{~mL})$ was refluxed for $0.5 \mathrm{~h}$ under argon. After being cooled to room temperature, the solvent was removed in a vacuum. A solution of 5-(4-tert-butylphenyl)- $1 H$-tetrazole [see the Supporting Information] (202 mg, $1 \mathrm{mmol})$ and toluene $(5 \mathrm{~mL})$ was added into the mixture. After the solution was heated for $8 \mathrm{~h}$, the solvent was removed in a vacuum and the crude product was purified by column chromatography $($ EtOAc/ hexane $=1 / 5)$ on silica gel to give pure compound 7a (387 mg, 65\% yield). Mp 298$301{ }^{\circ} \mathrm{C}$; IR (KBr) v 3058, 2972, 2886, 1613, 1560, 1447, 1407, 1268, 1056, $731 \mathrm{~cm}^{-1} ;{ }^{1} \mathrm{H}$ NMR $\left(\mathrm{CDCl}_{3}, 400 \mathrm{MHz}\right) \delta 8.19(\mathrm{dd}$, $J=7.6,1.2 \mathrm{~Hz}, 1 \mathrm{H}), 8.01-7.97(\mathrm{~m}, 3 \mathrm{H}), 7.91(\mathrm{dd}, J=8.0,3.2$ $\mathrm{Hz}, 1 \mathrm{H}), 7.84(\mathrm{dd}, J=7.6,4.4 \mathrm{~Hz}, 1 \mathrm{H}), 7.75(\mathrm{dd}, J=8.0,3.2 \mathrm{~Hz}$, $1 \mathrm{H}), 7.54-7.38(\mathrm{~m}, 7 \mathrm{H}), 7.21-7.14(\mathrm{~m}, 2 \mathrm{H}), 6.86(\mathrm{~d}, J=2.0 \mathrm{~Hz}$, $1 \mathrm{H}), 6.77-6.72(\mathrm{~m}, 2 \mathrm{H}), 1.34(\mathrm{~s}, 9 \mathrm{H}) ;{ }^{13} \mathrm{C} \mathrm{NMR}\left(\mathrm{CDCl}_{3}, 100 \mathrm{MHz}\right)$ $\delta 155.0149 .5,148.5,144.9,140.7,140.6,140.2,131.1,129.0$, $128.3,128.2,128.1,127.1,127.0,126.5,125.8,124.1,124.0,123.9$, $123.1,122.5,122.4,121.6,121.4,120.8,120.7,120.5,120.2,65.7$, 35.1, 31.1; MS (m/z, $\left.\mathrm{FAB}^{+}\right) 597.3$ (50), 595.3 (50), 307.1(100); HRMS calcd for $\mathrm{C}_{37} \mathrm{H}_{27}{ }^{81} \mathrm{BrN}_{2} \mathrm{O}$ 596.1286, found 597.1344, HRMS calcd for $\mathrm{C}_{37} \mathrm{H}_{27}{ }^{79} \mathrm{BrN}_{2} \mathrm{O}$ 594.1307, found 595.1372.

Synthesis of 2,7-Dibromo-2'-(4-tert-butylphenyl-1H-tetrazole5-yl)-9,9'-spirobifluorene (7b). Compound $6 \mathbf{b}$ (515 mg, $1 \mathrm{mmol})$ in thionyl chloride $(10 \mathrm{~mL})$ was refluxed for $0.5 \mathrm{~h}$ under argon. After the mixture was cooled to room temperature, the solvent was removed in a vacuum. The solution of 5-(4-tert-butylphenyl)- $1 H$ tetrazole $(202 \mathrm{mg}, 1 \mathrm{mmol})$ and toluene $(5 \mathrm{~mL})$ was added to the mixture. After the solution was heated for $8 \mathrm{~h}$, the solvent was removed and the crude product was purified by column chromatography on silica gel $(\mathrm{EtOAc} / \mathrm{hexanes}=1 / 5)$ to give pure compound $7 \mathbf{b}(530 \mathrm{mg}, 80 \%)$. Mp 369-371 ${ }^{\circ} \mathrm{C} ;{ }^{1} \mathrm{H}$ NMR $\left(\mathrm{CDCl}_{3}\right.$, $400 \mathrm{MHz}) \delta 8.20(\mathrm{dd}, J=8 \mathrm{~Hz}, 1.6 \mathrm{~Hz}, 1 \mathrm{H}), 8.01-7.98(\mathrm{~m}, 3 \mathrm{H})$, $7.92(\mathrm{~d}, J=8 \mathrm{~Hz}, 1 \mathrm{H}), 7.72(\mathrm{~d}, J=8 \mathrm{~Hz}, 2 \mathrm{H}), 7.54-7.49(\mathrm{~m}$, $5 \mathrm{H}), 7.46(\mathrm{t}, J=7.6 \mathrm{~Hz}, 1 \mathrm{H}), 7.23(\mathrm{t}, J=7.6 \mathrm{~Hz}, 1 \mathrm{H}), 6.85(\mathrm{~d}$, $J=1.6 \mathrm{~Hz}, 2 \mathrm{H}), 6.77(\mathrm{~d}, J=7.6 \mathrm{~Hz}, 1 \mathrm{H}), 1.58(\mathrm{~s}, 9 \mathrm{H}) ;{ }^{13} \mathrm{C} \mathrm{NMR}$ $\left(\mathrm{CDCl}_{3}, 100 \mathrm{MHz}\right) \delta 164.38,164.06,155.17,149.40,147.97$, $147.79,144.99,140.34,139.77,131.54,129.35,128.67,127.46$, $127.37,126.87,126.07,124.35,123.54,122.74,122.15,121.80$, 121.11, 121.03, 120.97, 66.02, 35.84, 31.89; $\mathrm{MS}\left(\mathrm{FAB}^{+}, \mathrm{m} / \mathrm{z}\right) 674.0$ (40); HRMS calcd for $\mathrm{C}_{26} \mathrm{H}_{16}{ }^{81} \mathrm{Br}^{81} \mathrm{Br}$ 676.0371, found 677.0430, HRMS calcd for $\mathrm{C}_{26} \mathrm{H}_{16}{ }^{79} \mathrm{Br}^{81} \mathrm{Br}$ 674.0391, found 675.0440, HRMS calcd for $\mathrm{C}_{26} \mathrm{H}_{16}{ }^{79} \mathrm{Br}^{79} \mathrm{Br}$ 672.0412, found 673.0483. Anal. Calcd for $\mathrm{C}_{26} \mathrm{H}_{16} \mathrm{Br}_{2}$ : C, 65.89, H, 3.89, N, 4.15. Found: C, 65.90, H, $3.85, \mathrm{~N}, 4.02$.

Synthesis of D1A1. By the Pd-catalyzed C-N bond formation reaction, the mixture of compound $7 \mathbf{a}(595 \mathrm{mg}, 1.0 \mathrm{mmol})$, diphenylamine (338 mg, $2 \mathrm{mmol}), \mathrm{Pd}(\mathrm{OAc})_{2}(0.03 \mathrm{mmol}, 6.72 \mathrm{mg}$ ), tri-tert-butyl phosphine $(2.4 \mathrm{~mL}, 0.05 \mathrm{M}$ in toluene), and sodium tert-butoxide $(192 \mathrm{mg}, 2 \mathrm{mmol})$ in dry toluene $(5 \mathrm{~mL})$ was refluxed for $8 \mathrm{~h}$. The mixture then was extracted with $\mathrm{CH}_{2} \mathrm{Cl}_{2}$, the organic layer was washed with water and dried over $\mathrm{MgSO}_{4}$, and the solvents were evaporated to dryness. Pure D1A1 was isolated by column chromatography on silica gel $($ EtOAc/ hexanes $=1 / 4)$ as a white solid (485 mg, $71 \%$ yield). Mp $277{ }^{\circ} \mathrm{C}$ (DSC); IR (KBr) $v$ 2975, 1616, 1595, 1495, 1452, 1293, 1272, 1024, 833, 752, 732, $698 \mathrm{~cm}^{-1} ;{ }^{1} \mathrm{H}$ NMR (DMSO- $\left.d_{6}, 400 \mathrm{MHz}\right) \delta 8.19(\mathrm{~d}, J=7.8 \mathrm{~Hz}$, $1 \mathrm{H}), 8.15(\mathrm{~d}, J=8.0 \mathrm{~Hz}, 1 \mathrm{H}), 8.05(\mathrm{~d}, J=7.6 \mathrm{~Hz}, 1 \mathrm{H}), 7.97(\mathrm{t}$, $J=8.9 \mathrm{~Hz}, 4 \mathrm{H}), 7.60(\mathrm{~d}, J=8.3 \mathrm{~Hz}, 2 \mathrm{H}), 7.45-7.40(\mathrm{~m}, 2 \mathrm{H})$, $7.33(\mathrm{~s}, 1 \mathrm{H}), 7.14-7.07(\mathrm{~m}, 5 \mathrm{H}), 6.99(\mathrm{~d}, J=8.4 \mathrm{~Hz}, 1 \mathrm{H}), 6.92(\mathrm{t}$, $J=7.3 \mathrm{~Hz}, 1 \mathrm{H}), 6.84(\mathrm{~d}, J=8.0 \mathrm{~Hz}, 4 \mathrm{H}), 6.75(\mathrm{~d}, J=7.5 \mathrm{~Hz}$, $1 \mathrm{H}), 6.61(\mathrm{~d}, J=7.5 \mathrm{~Hz}, 1 \mathrm{H}), 6.25(\mathrm{~s}, 1 \mathrm{H}), 1.30(\mathrm{~s}, 9 \mathrm{H}) ;{ }^{13} \mathrm{C} \mathrm{NMR}$ $\left(\mathrm{CDCl}_{3}, 100 \mathrm{MHz}\right) 163.7,163.5,154.5,149.1,148.2,148.0,146.8$, $144.5,140.3,140.1,139.7,130.7,128.7,128.6,127.9,127.8,127.7$, $126.7,126.2,125.4,123.7,123.5,122.8,122.1,121.1,120.5,120.4$, 120.2, 119.9, 117.3, 65.7, 35.2, 31.3; MS $\left(\mathrm{m} / \mathrm{z}, \mathrm{FAB}^{+}\right) 684(100)$, 683 (100), 508 (5), 460 (10), 307 (75), 289 (35); HRMS calcd for $\mathrm{C}_{49} \mathrm{H}_{37} \mathrm{~N}_{3} \mathrm{O}$ 683.2937, found 683.2934. Anal. Calcd for $\mathrm{C}_{49} \mathrm{H}_{37} \mathrm{~N}_{3^{-}}$ O: C, 86.06, H, 5.45, N, 6.14. Found: C, 85.98, H, 5.47, N, 6.16 .

Synthesis of D2A1. The mixture of compound $7 \mathbf{b}(1.17 \mathrm{~g}, 1.7$ mmol), diphenylamine (0.88 g, $5.2 \mathrm{mmol}), \mathrm{Pd}(\mathrm{OAc})_{2}(7.8 \mathrm{mg}, 0.04$ $\mathrm{mmol})$, tri-tert-butylphosphine $(2.0 \mathrm{~mL}, 0.05 \mathrm{M}$ in toluene), and sodium tert-butoxide (467 mg, $4.8 \mathrm{mmol})$ in dry toluene $(5 \mathrm{~mL}$ ) was refluxed for $8 \mathrm{~h}$. This mixture was extracted with $\mathrm{CH}_{2} \mathrm{Cl}_{2}$ and the organic layer was washed with water and dried over $\mathrm{MgSO}_{4}$. Pure D1A1 was isolated by column chromatography on silica gel $($ EtOAc/ hexanes $=1 / 4)(1.22 \mathrm{~g}, 82 \%$ yield $) . \mathrm{Mp} 406{ }^{\circ} \mathrm{C}(\mathrm{DSC})$; IR (KBr) $v 2952,1593,1493,1467,1261,1016,751,698 \mathrm{~cm}^{-1}$; 
${ }^{1} \mathrm{H} \mathrm{NMR}\left(\mathrm{CDCl}_{3}, 400 \mathrm{MHz}\right) \delta 8.07(\mathrm{~m}, 3 \mathrm{H}), 7.80(\mathrm{~d}, J=8.2 \mathrm{~Hz}$, $1 \mathrm{H}), 7.73(\mathrm{~d}, J=7.2 \mathrm{~Hz}, 1 \mathrm{H}), 7.69(\mathrm{~d}, J=0.8 \mathrm{~Hz}, 1 \mathrm{H}), 7.63(\mathrm{~d}$, $J=8.2 \mathrm{~Hz}, 2 \mathrm{H}), 7.55(\mathrm{~d}, J=8.2 \mathrm{~Hz}, 2 \mathrm{H}), 7.34(\mathrm{t}, J=7.2 \mathrm{~Hz}$, $1 \mathrm{H}), 7.29-7.21(\mathrm{~m}, 1 \mathrm{H}), 7.22(\mathrm{td}, J=7.5,0.8 \mathrm{~Hz}, 1 \mathrm{H}), 7.10-$ $7.06(\mathrm{~m}, 8 \mathrm{H}), 7.00(\mathrm{dd}, J=8.2,2.4 \mathrm{~Hz}, 2 \mathrm{H}), 6.95-6.86(\mathrm{~m}, 12 \mathrm{H})$, $6.50(\mathrm{~d}, J=1.6 \mathrm{~Hz}, 2 \mathrm{H}), 1,36(\mathrm{~s}, 9 \mathrm{H}) ;{ }^{13} \mathrm{C} \mathrm{NMR}\left(\mathrm{CDCl}_{3}, 100\right.$ MHz) 163.9, 163.8, 154.6, 149.0, 1458.9, 148.5, 146.9, 146.4, 144.6, 139.6, 136.1, 128.8, 128.5, 128.3, 127.4, 126.3, 126.2, 125.6, 123.8, $123.5,123.3,122.4,122.1,120.7,120.6,120.4,120.2,119.9,119.3$, 117.4, 65.8, 35.3, 31.4; MS (FAB $\left.{ }^{+}, m / z\right) 850.4$ (100); HRMS calcd for $\mathrm{C}_{61} \mathrm{H}_{46} \mathrm{~N}_{4} \mathrm{O}$ 850.3672, found 850.3666.

Photophysical Measurements. Steady-state absorption and emission spectra were recorded with a spectrophotometer and a fluorimeter, respectively. Nanosecond lifetime studies were performed with a photon-counting system with a hydrogen-filled or nitrogen lamp as the excitation source. The emission decays were analyzed by the sum of exponential functions, which allows partial removal of the instrument time broadening and consequently renders a temporal resolution of $\sim 200 \mathrm{ps}$.

The fluorescence upconversion measurements were performed with use of a femtosecond optically gated system, details of which have been described in a previous report. ${ }^{8,9}$ Briefly, the fundamental of a Ti:sapphire laser at $750-850 \mathrm{~nm}$ was used to produce second harmonics $(\mathrm{SH})$ at $375-425 \mathrm{~nm}$. The resulting fluorescence and the optical delayed remaining fundamental pulses were collected and focused on a BBO type-I crystal $(0.5 \mathrm{~mm})$ for the sum- frequency generation. The up-converted signal was then separated by an $\mathrm{F} / 4.9(f=380 \mathrm{~mm})$ single monochromator and detected via a photon counting PMT. The cross correlation between $\mathrm{SH}$ and the fundamental had a full width at half-maximum (fwhm) of $\sim 150$ fs, which was chosen as a response function of the system. In addition, a Berek's variable waveplate was placed in the pump beam path to ensure that the polarization of the pump laser was set at the magic angle $\left(54.7^{\circ}\right)$ with respect to that of the probe laser (or detecting system) to eliminate the fluorescence anisotropy.

Acknowledgment. We thank Prof. C. C. Wang of Soochow University for his instructive suggestions on the crystal structures. This work was financially supported by the National Science Council of Taiwan.

Supporting Information Available: Detail experimental procedures and spectroscopic characterization of compounds $\mathbf{1 b}, \mathbf{8 a}$, 8b, D1, D2, A1, A2, 12, and 13, ${ }^{1} \mathrm{H},{ }^{13} \mathrm{C}$ NMR spectra of new compounds, crystal data and ORTEP diagrams of D1A1, D1A2, D2A1, and D2A2, cyclic voltammetry data of D1, D2, A1, A2, D1A1, D1A2, D2A1, and D2A2, and characteristics of absorption and emission spectra in different solvents of D1A2, D2A1, and D2A2. This material is available free of charge via the Internet at http://pubs.acs.org.

JO0512047 